Article

\title{
Quantifying the UK Online Interest in Substances of the EU Watchlist for Water Monitoring: Diclofenac, Estradiol, and the Macrolide Antibiotics
}

\author{
Amaryllis Mavragani ${ }^{1}$, Karla Sypsa ${ }^{2}$, Alexia Sampri ${ }^{1}$ and Konstantinos P. Tsagarakis ${ }^{1, *}$ \\ 1 Business and Environmental Technology Economics Lab, Environmental Engineering Department, \\ Democritus University of Thrace, 67100 Xanthi, Greece; amavraga@env.duth.gr (A.M.); \\ alexia93sab@gmail.com (A.S.) \\ 2 Department of Pharmacy and Forensic Science, King's College London, Fifth Floor, \\ Franklin-Wilkins Building, Waterloo Campus, London SE1 9NH, UK; lamprini.sypsa@kcl.ac.uk \\ * Correspondence: ktsagar@env.duth.gr; Tel.: +30-2541-079-397
}

Academic Editor: Mustafa M. Aral

Received: 26 September 2016; Accepted: 9 November 2016; Published: 18 November 2016

\begin{abstract}
Due to the increased interest in micropollutants, this paper aims at quantifying and analyzing the UK online interest in Diclofenac, Estradiol, Azithromycin, Clarithromycin, and Erythromycin, substances included in the EU watchlist for monitoring, in order to examine if the public's online behavior and the use of these substances, in terms of issued prescriptions, are correlated. Using time series data from Google Trends from January 2004 to December 2014, an analysis of these substances in the UK, and in each UK region, i.e., England, Wales, Scotland, and Northern Ireland, is at first performed, followed by an analysis of interest by substance. The results show high interest in Diclofenac with a slight decline, while the Macrolides are significantly less popular though increasing. For Estradiol, the interest is low and declining throughout the examined period, in contrast to the scientific community, where Estradiol is the most studied substance. Prescription items and Google hits are highly correlated in the UK for Diclofenac, Azithromycin, and Clarithromycin, while no correlation is observed for Estradiol. Results from this study indicated that online search traffic data can be valuable in examining the public's online behavior towards the monitored micropollutants, and could assist with the evaluation and forecasting of their concentrations in the waste, surface, and ground water in the UK.
\end{abstract}

Keywords: azithromycin; big data; clarithromycin; diclofenac; erythromycin; estradiol; Google trends; macrolide antibiotics; online behavior; prescriptions

\section{Introduction}

The EU issued its first Directive for Water Policy, Directive 2000/60/EC, in 2000, where high risk substances were defined and prioritized [1], and Directive 2008/105/EC approved a list of 33 priority substances and their Environmental Quality Standards [2]. Following this, in Directive 2013/39/EU [3] a list of 45 priority substances was proposed, including Diclofenac, 17-Alphaethinylestradiol (EE2), and 17-Beta-Estradiol (E2) as recommended for monitoring. This was later implemented in Decision 2015/495 [4], issued on 20 March 2015, where the EU established a list of 10 substances to be monitored for Environmental Quality Standards in the field of Water Policy. This list consists of 17 organic compounds, namely 17-Alpha-ethinylestradiol, 17-Beta-estradiol Estrone, Diclofenac, 2,6-di-tetr-butyl-4-methylphenol, 2-ethylhexyl-4-methoxycinnamate, Macrolide Antibiotics (Azithromycin, Clarithromycin, and Erythromycin), Methiocrab, Neonicotinoids (Imidacloprid, Thiacloprid, Thimamethoxam, Clothianidin, and Acetamiprid), Oxadiazon, and 
Triallate. These substances do not have a legal discharge limit, but need to be monitored as they are suggested to potentially be harmful for the environment.

Diclofenac is a widely used non-steroidal-anti-inflammatory drug (NSAID) [5], commonly administered orally or dermally, as well as intramuscularly and rectally. It has analgesic, anti-inflammatory, and antipyretic properties, and is mainly used in inflammatory diseases, such as rheumatoid arthritis, as well as for the treatment of short-term conditions, like migraines, fever, menstrual pain, and in postoperative pain [6]. Being a non-selective cyclooxygenase (COX) inhibitor, Diclofenac almost equally blocks both COX-1 and COX-2, with the inhibition of COX-1 being associated with gastrointestinal effects, such as gastric ulcers, and the inhibition of COX-2 causing atherosclerotic complications leading to myocardial infarction (MI) and stroke [7]. The increased risk of cardiovascular complications, such as acute MI, has been linked to both low and high doses of Diclofenac [8]. Despite being a non-selective inhibitor, Diclofenac has a similar atherosclerotic risk to that of selective COX-2 inhibitors, which, even though has not been fully understood, is probably due to a moderate COX-2 selectivity [9].

Oral Diclofenac is available as an over the counter medication in many European countries. However, due to the cardiovascular adverse effects caused by prolonged use of Diclofenac, some countries, including the United Kingdom, changed their policy and added high strengths of oral Diclofenac to the prescription-only medication list [10]. Despite the increased risk of cardiovascular complications being known for several years, Diclofenac is still one of the most popular NSAIDs, with its sales worldwide overriding those of less risky non-selective NSAIDs, like Naproxen [11].

Apart from risks towards human health, Diclofenac can also have a negative impact on the environment. Approximately $70 \%$ of an oral Diclofenac dose is excreted through the urine within three days of administration, mostly as conjugates of Diclofenac metabolites, and less than $1 \%$ is excreted as unchanged drug [12-14]. After their use by patients in the community, medicines can reach the aquatic environment via faeces and urine [15]. Diclofenac is not fully removed by wastewater treatment [14,16-18], with its removal through this process varying from $0 \%$ to $80 \%$ [18]. As Diclofenac is not highly biodegradable [14], it is detected in WWTP effluents [19], surface water, and groundwater [18], and unsuccessful treatment of water aiming to remove pharmaceutical residues has led to Diclofenac being traced in the tap water of several European countries in the past [20]. Diclofenac tends to remain in the aqueous phase once in the sewage system, as it is relatively water soluble and has a low tendency for absorption onto organic matter [20]. The presence of chlorine in the structure of Diclofenac has been linked to the failure of completely removing Diclofenac by conventional methods, such as applying activated sludge (CAS), and an increased persistence to more advanced treatments, such as membrane bioreactor (MBR) [20].

Additionally, the veterinary use of Diclofenac in cattle has caused a significant decline in the population of vultures in India, which after consuming the corpses of dead cattle that had been treated with Diclofenac, developed severe renal failure $[15,21]$. Several studies have been conducted in order to measure the extent of damage caused by Diclofenac to aquatic organisms. These studies have shown that Diclofenac can reduce the feeding rate and activity in the Japanese medaka fish [22]. Furthermore, Diclofenac has been shown to accumulate in the liver and kidney of the rainbow trout, indicating that subchronic exposure to Diclofenac can have a negative impact on the species' health, leading to tissue damage, as the lowest observed effect concentration for cytopathology for this species occurs at just $1 \mu \mathrm{g} / \mathrm{L}[15,23,24]$. Another study has shown that the concentration of Diclofenac in the bile of bream and roach from a lake receiving municipal wastewater effluents was significantly higher than the concentration of Diclofenac detected in the lake water, indicating that it can accumulate in aquatic organisms [14].

Based on the above, it has been reported that Diclofenac can be harmful for environmental health [16] and, though there are no legal discharge limits, monitoring of its concentrations in the aquatic environment are required in order to preserve good quality of water [17]. 
The Macrolide Antibiotics, including Azithromycin, Clarithromycin, and Erythromycin, are a very commonly used group of antibacterial antibiotics [25]. Erythromycin was derived from the Streptomyces spp. in 1952, whereas Azithromycin and Clarithromycin were later derived from Erythromycin [26]. These antibiotics are frequently used in human and in veterinary medicine, mainly for the treating and preventing of bacterial infections [25,27].

As the Macrolides have a similar activity spectrum to that of the penicillins, they are commonly used in the treatment of penicillin allergic patients. They are mainly effective against Gram positive cocci apart from enterococci, against some Gram negative bacteria, as well as against atypical pathogens [28]. Despite most of the Macrolides having a relatively similar spectrum of activity, Azithromycin has a decreased activity towards Gram positive microorganisms and an enhanced activity towards Gram negative, including Haemophilus influenza, and Clarithromycin has a relatively increased activity, both in comparison to Erythromycin [29].

Clarithromycin is most commonly used alongside amoxicillin in the treatment of community acquired pneumonia and as part of the triple therapy used for the eradication of Helicobacter pylori [29,30], whereas Azithromycin and Erythromycin are used in the treatment of uncomplicated genital chlamydial infection and in acute non-specific urethritis [29]. The Macrolides have a relatively mild side effect profile, nevertheless, Erythromycin has been noted to have an increased prokinetic activity, causing gastrointestinal side effects more frequently than the other Macrolides, and in some rare occasions it has been linked to causing Torsades de pointes. However, this side effect is only important in patients with heart disease or other relevant comorbidities [31-33].

The environmental concerns regarding the impact of the Macrolides on the environment are mostly focused on the continuously increasing antimicrobial resistance. Antibiotics most commonly end up in the sewage system through excretion from humans, disposing of antibiotics in the toilet, as well as from runoff from agricultural facilities, and hospital waste. The excretion rate of the Macrolides can reach 60\%, and they have been detected in wastewater treatment plants influents in the USA at very high concentrations (up to $1.5 \mu \mathrm{g} / \mathrm{L}$ ) [34]. In specific, Clarithromycin has been detected in effluents worldwide in concentrations ranging from 12 to $536 \mathrm{ng} / \mathrm{L}$ [35-37].

A major issue in the removal of the Macrolide Antibiotics from wastewater is that conventional wastewater treatment plants fail to fully remove them, resulting in their detection in treated effluents, surface water, and groundwater [25]. Yet, secondary wastewater treatment with activated sludge has been proven to be more successful $[27,34]$. They are included in the EU list for monitoring, as they are regarded, even at low concentrations, as possibly harmful to environmental health [25]. Apart from concerns that the Macrolide Antibiotics in wastewater can contribute to increasing antimicrobial resistance, studies have shown that Clarithromycin and Erythromycin have an increased toxicity, causing growth inhibition against algae and other aquatic photoautotrophs with a no-observed-effect concentration (NOEC) for Clarithromycin at just $2.45 \mu \mathrm{g} / \mathrm{L}$.

$17 \alpha$-ethinylestradiol (EE2) is a synthetic steroid hormone produced from the natural hormone $17 \beta$-estradiol (E2). EE2 is widely used as the estrogen component in combined oral contraceptives. It is also available as a transdermal patch and a vaginal ring for contraceptive purposes. Additionally, EE2 can be used for emergency contraception in combination with other hormones, for the treatment of acne, hirsutism, as well as for hormone replacement treatment in menopause [26]. The estrogen component of combined oral contraceptives has been linked to increased risk of venous thromboembolism, thus it is advised that the lowest effective concentration of estrogen is prescribed [38]. $17 \alpha$-ethinylestradiol is widely detected in surface waters worldwide, in concentrations at several ng/L, with EE2 being the most persistent in the aqueous environment [39]. The no effect concentration for E2 and EE2 has been estimated to be $2 \mathrm{ng} / \mathrm{L}$ and $0.1 \mathrm{ng} / \mathrm{L}$, respectively [40]. The presence of EE2 in wastewater is very concerning as it has been linked to the feminization of certain aquatic species, such as the male Mediterranean swordfish, the rainbow trout, and the cyprinids [41].

As the need to further examine the impact that micropollutants have on the environment has increased [16], this study aims at exploring the public's interest in Diclofenac, Estradiol, Azithromycin, 
Clarithromycin, and Erythromycin in the UK. In order to gain access to such vast amounts of information, namely Big Data, we use data from online search queries. One of the most popular tools to access these data is Google Trends [42], an open Google tool that shows what's trending.

Online search traffic data have been proven effective in analyzing online interest [43], and have been highly used in research over the last few years for analyzing online behavior. Data from Google Trends are suggested to be valid [44] and significantly contributing to forecastings [45] and in measuring public interest, subject to the careful selection of the terms to be examined [46]. Google Trends has the advantage of providing us with the revealed and not the stated data, so the public's online behavior is more accurately depicted, contrary to conventional methods of measuring public interest. Thus Google Trends is becoming all the more popular in various academic fields, especially in medical/health [47-62] and environmental issues [63-66]. Indicative examples include the detection of Tuberculosis outbreaks [48], the 2014 Ebola outbreak [49], flu predictions [61] and spreading [62], biodiversity [65], and interest in various environmental terms [63,66]. As indicated, the analysis of public interest is valuable in subjects concerning environmental and human health, thus, as the scientific interest in micropollutants is increasing, it is interesting to examine how the online searches are related to the use of these substances.

The aim of this paper is to quantify and analyze the public's online interest in Diclofenac, Estradiol, Azithromycin, Clarithromycin, and Erythromycin in the UK, and further compare the interest to the prescription volumes, and examine if any correlations between them exist. In showing that there is indeed a correlation between online interest and issued prescriptions, it is suggested that there exists a casual relationship between the interest in these terms and the actual usage of these substances. The rest of the paper is structured as follows: Section 2 consists of the data collection procedure and the method used to evaluate the online interest, Sections 3 and 4 consists of the results and discussion of our analysis, and Section 5 consists of the overall conclusions and further research suggestions.

\section{Data and Method}

Google Trends' [42] data from January 2004 to December 2014 are used to analyze the online interest in the terms 'Diclofenac', 'Estradiol', 'Azithromycin', 'Clarithromycin', and 'Erythromycin' in the UK. Data from Google Trends are downloaded online in '*...".sv' format and are normalized over the selected time-frame as follows: "each data point is divided by the total searches of the geography and time range it represents, to compare relative popularity. The resulting numbers are then scaled to a range of 0 to 100" [67].

Let $D_{t_{i}}, E S_{t_{i}}, A_{t_{i}}, C_{t_{i}}$, and $E_{t_{i}}$ be the weekly hits of the downloaded Google Trends' data for the terms 'Diclofenac', 'Estradiol', 'Azithromycin', 'Clarithromycin', and 'Erythromycin' of the $i$-th region, respectively. $D_{t_{p i}}, E S_{t_{p i}}, A_{t_{p i}}, C_{t_{p i}}$, and $E_{t_{p i}}$ denote the percentized weekly hits of their respective normalized Google searches, using Equations (1)-(5):

$$
\begin{aligned}
D_{t_{p i}} & =\frac{D_{t_{i}}}{D_{t_{i}}+E S_{t_{i}}+A_{t_{i}}+C_{t_{i}}+E_{t_{i}}} \\
E S_{t_{p i}} & =\frac{E S_{t_{i}}}{D_{t_{i}}+E S_{t_{i}}+A_{t_{i}}+C_{t_{i}}+E_{t_{i}}} \\
A_{t_{p i}} & =\frac{A_{t_{i}}}{D_{t_{i}}+E S_{t_{i}}+A_{t_{i}}+C_{t_{i}}+E_{t_{i}}} \\
C_{t_{p i}} & =\frac{C_{t_{i}}}{D_{t_{i}}+E S_{t_{i}}+A_{t_{i}}+C_{t_{i}}+E_{t_{i}}} \\
E_{t_{p i}}= & \frac{E_{t_{i}}}{D_{t_{i}}+E S_{t_{i}}+A_{t_{i}}+C_{t_{i}}+E_{t_{i}}}
\end{aligned}
$$


The relative changes between the substances' Worldwide interest is examined for reference, followed by the change in online interest for each substance individually in England, Wales, Scotland, and Northern Ireland, in addition to a comparative analysis of the five substances in the UK.

Furthermore, the total prescriptions issued for all drugs consisting of the respective chemical substance per each examined term and the total cost per substance per year in England [68], Wales [69], Scotland [70], and Northern Ireland [71] over the examined period are examined, which are then compared and analyzed in relation to the change in online interest. In addition, the total scientific interest based on Scopus searches for published papers with UK affiliation and in total, consisting of these substances in the 'Article Title-Abstract-Keywords' field, is examined and then compared to the Worldwide and UK online interest. Note that the selected papers include 'Articles', 'Reviews', 'Letters', 'Notes', and 'Short Surveys'.

Based on our results, we examine if the relative interest can be a predictor of the use of these substances in the UK, and any potential harm in environmental health, and how data from online search queries can be valuable towards this direction.

\section{Results}

This Section consists of the analysis of (a) Worldwide's and UK's online interest in 'Diclofenac', 'Estradiol', 'Azithromycin', 'Clarithromycin', and 'Erythromycin' from January 2004 to December 2014; (b) the regional interest in these terms for the same period in England, Wales, Scotland, and Northern Ireland; (c) each individual term's change in online interest in the UK; (d) the yearly total prescription items and total cost $(£)$ per substance in each region; (e) the scientific interest; and (f) the correlations between them.

\subsection{Worldwide and UK's Online Interest}

Figure 1 depicts the change in (a) the Worldwide and (b) UK's yearly averages of the percentized hits for the terms 'Diclofenac', 'Estradiol', 'Azithromycin', 'Clarithromycin', and 'Erythromycin' from January 2004 to December 2014. Tables 1 and 2 consist of the percentized hits' yearly averages in these terms in the same period Worldwide and in the UK, respectively.

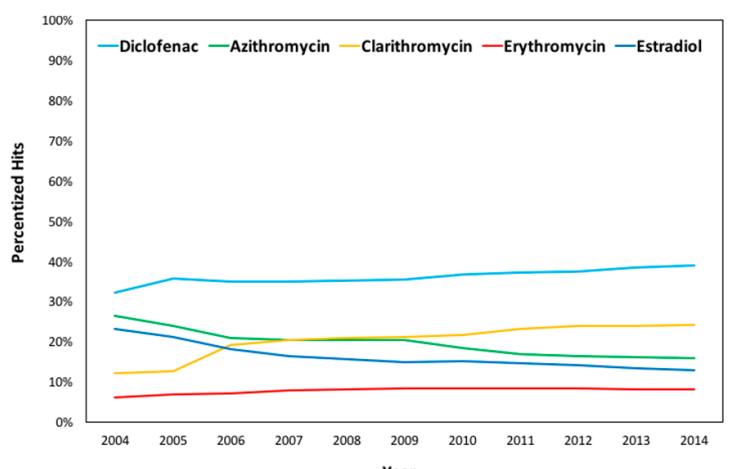

(a)

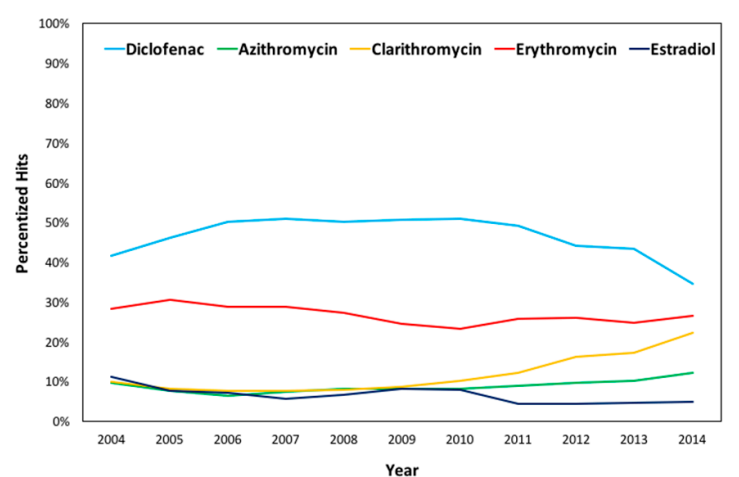

(b)

Figure 1. Yearly Averages of the (a) Worldwide and (b) UK Percentized Hits from 2004 to 2014.

As presented in Table 1, the yearly averages for the Worldwide interest show that the most popular amongst the examined substances is Diclofenac (36.05\%), followed by Clarithromycin $(20.27 \%)$, Azithromycin (19.61\%), Estradiol (16.29\%), and Erythromycin (7.77\%) in that order.

In the UK, results showed that Diclofenac, though first amongst the five substances in terms of online searches, showed a slight decline in interest in 2014 compared to 2004, the same as Estradiol, though with variations throughout the examined period. In contrast, the Macrolides of the EU watchlist Azithromycin and Clarithromycin show an increased interest over the examined period, while Erythromycin shows a slight decrease from 2004 to 2014. 
Table 1. Worldwide Yearly Averages of the Percentized Hits in the Five Examined Substances from 2004 to 2014.

\begin{tabular}{cccccc}
\hline Year & Diclofenac & Estradiol & Azithromycin & Clarithromycin & Erythromycin \\
\hline 2004 & $32.19 \%$ & $23.08 \%$ & $26.39 \%$ & $12.19 \%$ & $6.15 \%$ \\
2005 & $35.62 \%$ & $21.04 \%$ & $23.84 \%$ & $12.70 \%$ & $6.81 \%$ \\
2006 & $34.79 \%$ & $18.05 \%$ & $20.82 \%$ & $19.18 \%$ & $7.16 \%$ \\
2007 & $35.01 \%$ & $16.40 \%$ & $20.43 \%$ & $20.35 \%$ & $7.80 \%$ \\
2008 & $35.15 \%$ & $15.61 \%$ & $20.42 \%$ & $20.75 \%$ & $8.07 \%$ \\
2009 & $35.29 \%$ & $14.91 \%$ & $20.42 \%$ & $21.13 \%$ & $8.25 \%$ \\
2010 & $36.63 \%$ & $14.98 \%$ & $18.33 \%$ & $21.71 \%$ & $8.34 \%$ \\
2011 & $37.20 \%$ & $14.58 \%$ & $16.95 \%$ & $23.03 \%$ & $8.24 \%$ \\
2012 & $37.41 \%$ & $14.21 \%$ & $16.23 \%$ & $23.86 \%$ & $8.30 \%$ \\
2013 & $38.44 \%$ & $13.46 \%$ & $15.99 \%$ & $23.95 \%$ & $8.16 \%$ \\
2014 & $38.81 \%$ & $12.89 \%$ & $15.95 \%$ & $24.14 \%$ & $8.21 \%$ \\
Average & $36.05 \%$ & $16.29 \%$ & $19.61 \%$ & $20.27 \%$ & $7.77 \%$ \\
\hline
\end{tabular}

Table 2. Yearly Averages of the Percentized Hits in the Five Examined Substances in the UK from 2004 to 2014.

\begin{tabular}{cccccc}
\hline Year & Diclofenac & Estradiol & Azithromycin & Clarithromycin & Erythromycin \\
\hline 2004 & $41.55 \%$ & $11.07 \%$ & $9.53 \%$ & $9.76 \%$ & $28.09 \%$ \\
2005 & $46.11 \%$ & $7.66 \%$ & $7.70 \%$ & $8.18 \%$ & $30.36 \%$ \\
2006 & $50.00 \%$ & $7.06 \%$ & $6.42 \%$ & $7.69 \%$ & $28.82 \%$ \\
2007 & $50.82 \%$ & $5.61 \%$ & $7.30 \%$ & $7.49 \%$ & $28.77 \%$ \\
2008 & $50.13 \%$ & $6.55 \%$ & $8.09 \%$ & $7.92 \%$ & $27.30 \%$ \\
2009 & $50.60 \%$ & $8.05 \%$ & $8.19 \%$ & $8.69 \%$ & $24.47 \%$ \\
2010 & $50.92 \%$ & $7.78 \%$ & $8.04 \%$ & $10.12 \%$ & $23.14 \%$ \\
2011 & $48.96 \%$ & $4.40 \%$ & $8.80 \%$ & $12.08 \%$ & $25.76 \%$ \\
2012 & $44.10 \%$ & $4.33 \%$ & $9.53 \%$ & $16.03 \%$ & $26.01 \%$ \\
2013 & $43.38 \%$ & $4.55 \%$ & $10.05 \%$ & $17.25 \%$ & $24.77 \%$ \\
2014 & $34.53 \%$ & $4.91 \%$ & $12.06 \%$ & $22.19 \%$ & $26.32 \%$ \\
Average & $46.46 \%$ & $6.54 \%$ & $8.70 \%$ & $11.58 \%$ & $26.71 \%$ \\
\hline
\end{tabular}

Overall, in the UK, Diclofenac is the most searched substance out of the five, with Erythromycin, Clarithromycin, Azithromycin, and Estradiol following in that order. Interestingly enough, UK does not follow the Worldwide trend, with Erythromycin, though the second most searched term, being last in Worldwide interest.

\subsection{Regional Online Interest}

Table 3 consists of the percentage averages from 2004 to 2014 of the examined terms in England, Wales, Scotland, and Northern Ireland, while the yearly averages of each substance in the four regions can be found in Appendix A. Figure 2 depicts the change in the yearly averages of the percentized hits for the terms 'Diclofenac', 'Estradiol', 'Azithromycin', 'Clarithromycin', and 'Erythromycin' in (a) England; (b) Wales; (c) Scotland; and (d) Northern Ireland from 2004 to 2014.

Table 3. Percentage Averages from 2004 to 2014 for the five examined substances in England, Wales, Scotland, and Northern Ireland.

\begin{tabular}{cccccc}
\hline Region & Diclofenac & Estradiol & Azithromycin & Clarithromycin & Erythromycin \\
\hline England & $46.25 \%$ & $6.67 \%$ & $9.03 \%$ & $11.59 \%$ & $26.47 \%$ \\
Wales & $37.29 \%$ & $8.44 \%$ & $11.03 \%$ & $13.01 \%$ & $30.22 \%$ \\
Scotland & $39.66 \%$ & $10.19 \%$ & $11.29 \%$ & $15.28 \%$ & $23.58 \%$ \\
N. Ireland & $35.63 \%$ & $11.04 \%$ & $12.26 \%$ & $16.63 \%$ & $24.44 \%$ \\
\hline
\end{tabular}




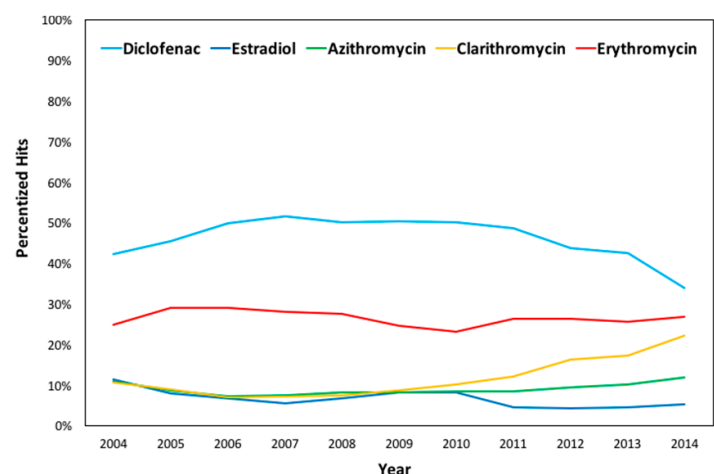

(a)

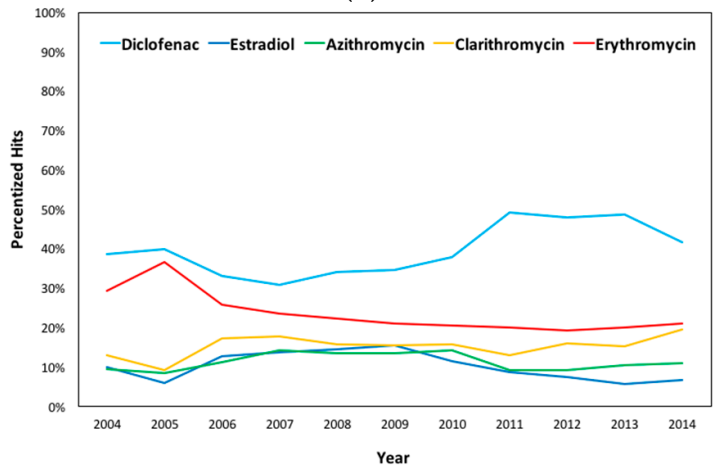

(c)

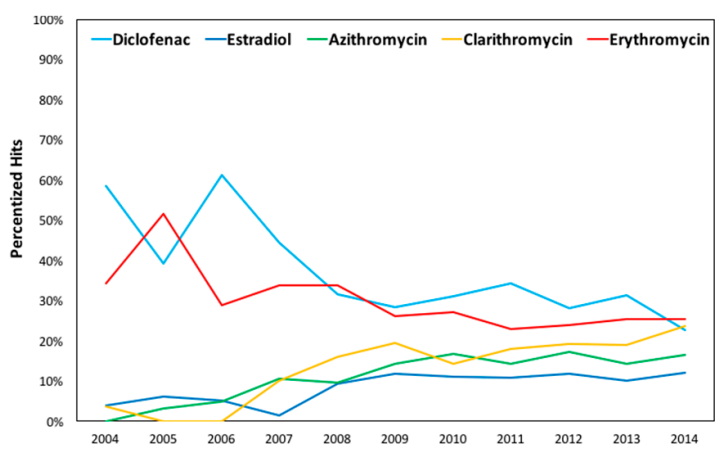

(b)

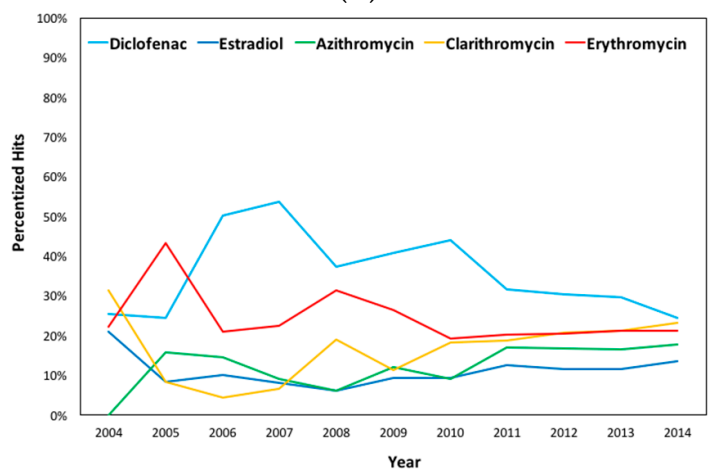

(d)

Figure 2. Yearly Averages of the Percentized Hits in (a) England; (b) Wales; (c) Scotland; and (d) Northern Ireland in Diclofenac, Estradiol, Azithromycin, Clarithromycin, and Erythromycin from 2004 to 2014 .

Overall, the results showed that in each of UK's regions, i.e., England, Wales, Scotland, and Northern Ireland, Diclofenac is the most searched term amongst the ones examined, followed by Erythromycin, Clarithromycin, Azithromycin, and Estradiol in that order, with Clarithromycin, Azithromycin, and Estradiol showing significantly less online interest.

More specifically, results revealed that in England Diclofenac is the most searched substance with an overall average of $46.25 \%$, followed by Erythromycin $(26.47 \%)$, Clarithromycin $(11.59 \%)$, Azithromycin (9.03\%), and Estradiol (6.67\%) (Table 3). In Wales, Scotland, and Northern Ireland, the order of online popularity of the five substances is the same as in England, i.e., Diclofenac (37.29\%, 39.66\%, and 35.63\%, respectively), Erythromycin $(30.22 \%, 23.58 \%$, and $24.44 \%$, respectively), Clarithromycin (13.01\%, 15.28\%, and 16.63\%, respectively), Azithromycin (11.03\%, 11.29\%, 12.26\%, respectively), and Estradiol (8.44\%, 10.19\%, and 11.04\%) (Table 3).

Table 4 consists of the percentage differences of the yearly averages of the percentized hits between the years 2004 and 2014 for the terms 'Diclofenac', 'Azithromycin', 'Clarithromycin', 'Erythromycin', and 'Estradiol' in the UK, England, Wales, Scotland, Northern Ireland, and Worldwide.

Table 4. Worldwide, UK, and Regional Percentage Differences between the Years 2004 and 2014.

\begin{tabular}{cccccc}
\hline Region & Diclofenac & Estradiol & Azithromycin & Clarithromycin & Erythromycin \\
\hline Worldwide & $20.56 \%$ & $-44.15 \%$ & $-39.55 \%$ & $98.02 \%$ & $33.47 \%$ \\
UK & $-16.90 \%$ & $-55.69 \%$ & $26.47 \%$ & $127.34 \%$ & $-6.28 \%$ \\
England & $-19.64 \%$ & $-54.78 \%$ & $7.77 \%$ & $109.02 \%$ & $8.56 \%$ \\
Wales & $-61.47 \%$ & $224.48 \%$ & $435.49 \% *$ & $551.03 \%$ & $-26.13 \%$ \\
Scotland & $7.70 \%$ & $-31.69 \%$ & $18.77 \%$ & $51.58 \%$ & $-28.11 \%$ \\
N. Ireland & $-3.52 \%$ & $-35.87 \%$ & $12.90 \% *$ & $-26.22 \%$ & $-5.26 \%$ \\
\hline
\end{tabular}

Note: ${ }^{*}$ The differences are calculated based on the years 2005 and 2014. 
In England, Diclofenac and Estradiol show significant decrease, in Wales a decrease is observed only in Diclofenac and Erythromycin, while in Scotland in Erythromycin and Estradiol. In Northern Ireland the interest in all substances apart from Azithromycin is decreasing, but minimal increase is observed in the case of Diclofenac and Erythromycin. Overall, the only substance that shows an increase in all regions, i.e., UK, England, Wales, Scotland, Northern Ireland, and Worldwide, is Clarithromycin.

\subsection{Online Interest by Substance}

This section consists of the individual analysis for each of the five terms' change in online interest in the UK in the selected period. Figures 3-7 depict the terms' (a) normalized hits in the UK from January 2004 to December 2014 and (b) the yearly averages of the percentized hits in England, Wales, Scotland, and Northern Ireland. Figures 3 and 4 depict the online change in interest in 'Diclofenac' and 'Estradiol', respectively, while Figures 5-7 depict the online change in interest in the Macrolides, i.e., 'Azithromycin', 'Clarithromycin', and 'Erythromycin', respectively.

In Diclofenac, as is observed in Figure 3, the online interest has relatively small variations throughout the selected period, where the peak in interest in the selected period is in June-July 2013.

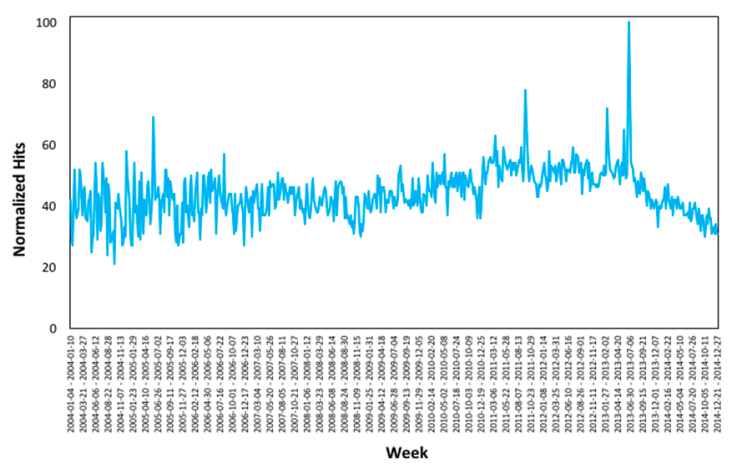

(a)

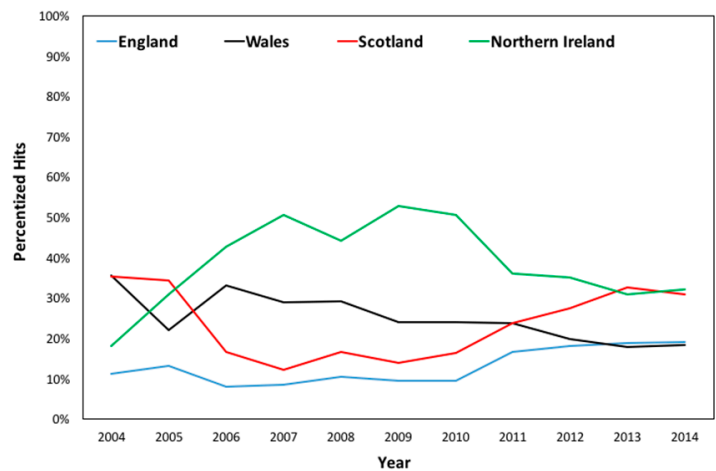

(b)

Figure 3. Diclofenac's (a) Normalized Hits in the UK and (b) Regional Percentized Hits Averages 2004-2014.

As intake of Diclofenac was suggested to have an increased risk for cardiovascular diseases, possibly even at small doses, and following the MHRA's concern on its availability in August 2013, Diclofenac was switched from being an over-the-counter drug to presciption only on 15 January 2015 [72]. This is indicative that incidence occurrence is instantly depicted in online searches.

Estradiol's online interest has decreased since 2004 in the UK, compared to other substances, as shown in Figure 4.

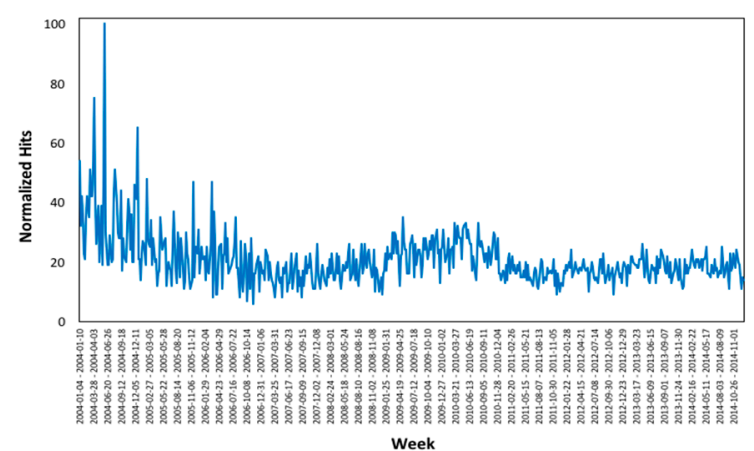

(a)

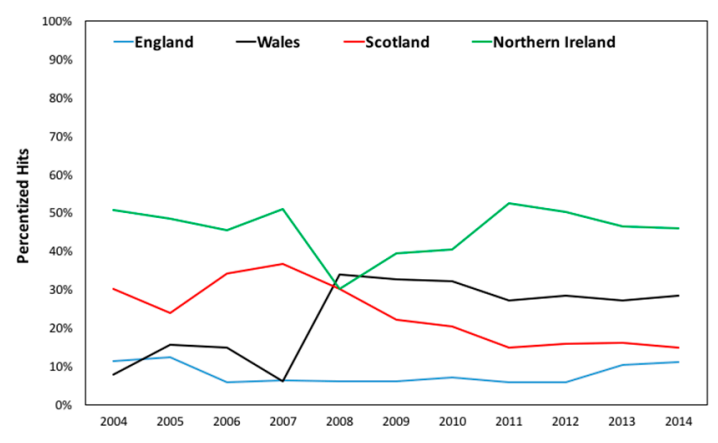

(b)

Figure 4. Estradiol's (a) Normalized Hits in the UK and (b) Regional Percentized Hits Averages 2004-2014. 
Though the highest online interest is observed in Northern Ireland compared to the other regions, the only significant increase in the substance's online interest is observed in Wales after 2008.

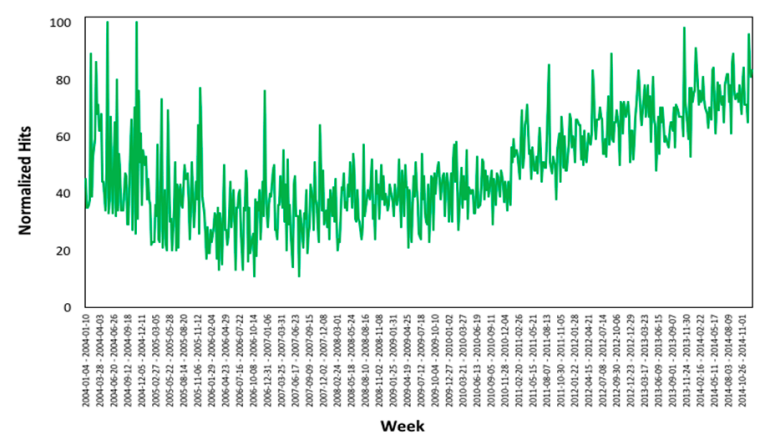

(a)

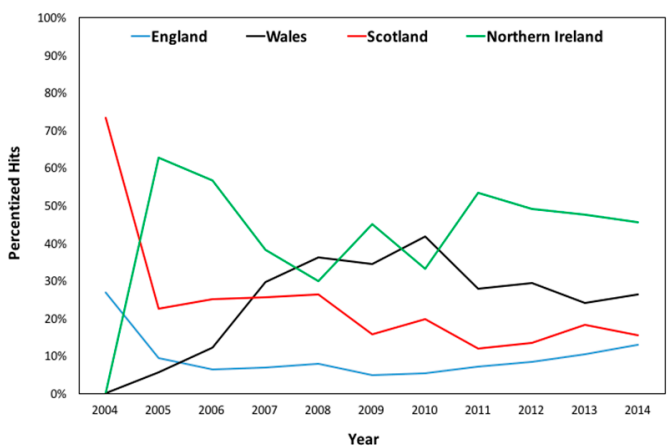

(b)

Figure 5. Azithromycin's (a) Normalized Hits in the UK and (b) Regional Percentized Hits Averages 2004-2014.

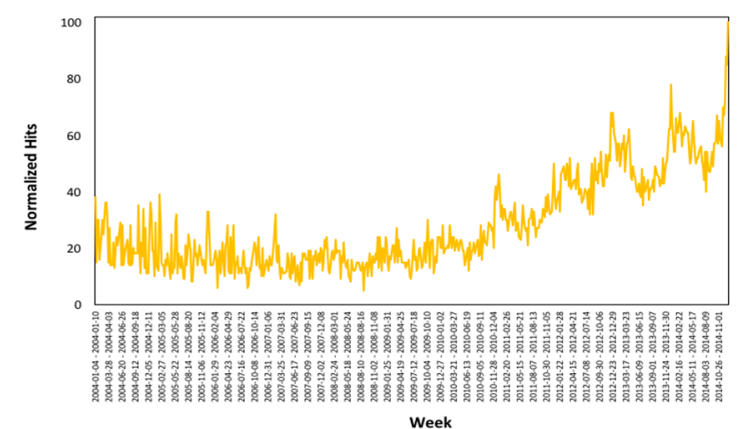

(a)

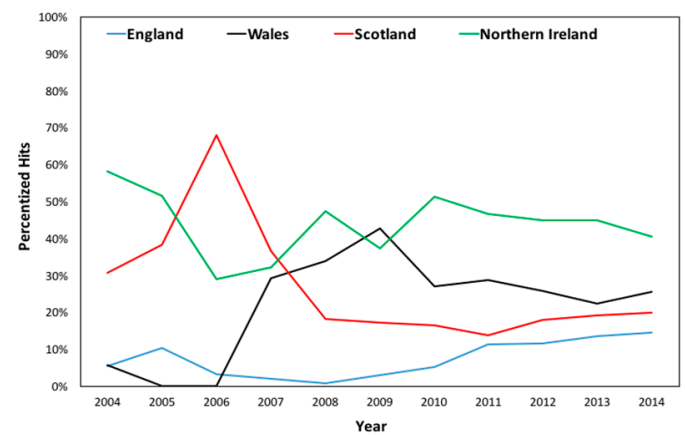

(b)

Figure 6. Clarithromycin's (a) Normalized Hits in the UK \& (b) Regional Percentized Hits Averages 2004-2014.

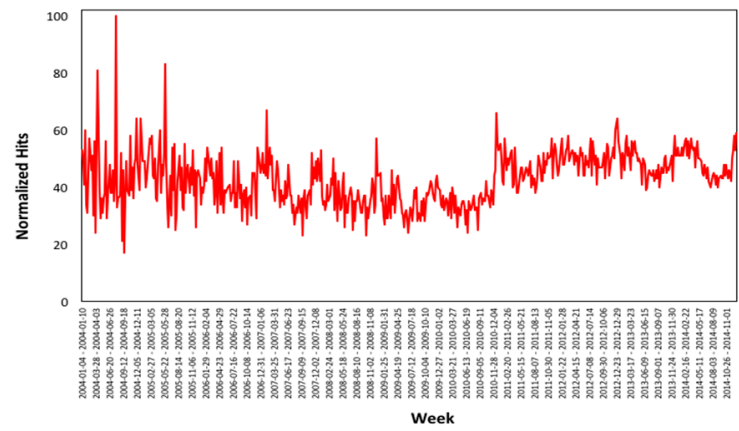

(a)

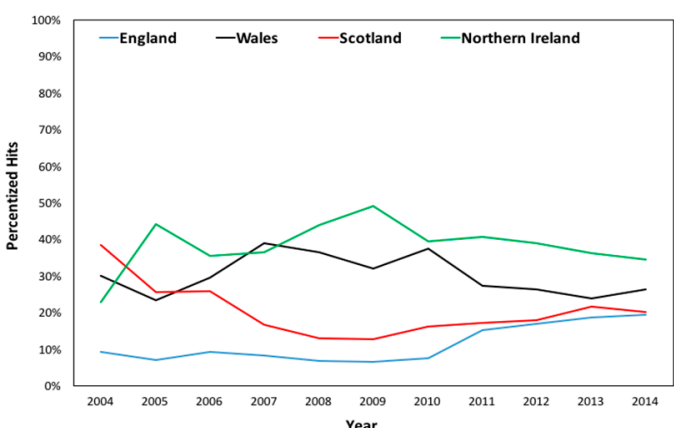

(b)

Figure 7. Erythromycin's (a) Normalized Hits in the UK and (b) Regional Percentized Hits Averages 2004-2014.

For the Macrolides, Azithromycin and Clarithromycin showed an increase in online interest over the last years, while the interest in Erythromycin is relatively stable, compared to the other substances. More specifically, for Azithromycin, the regional interest is the lowest in England, followed by Scotland, Wales, and Northern Ireland in that order, though a significant increase is observed in Wales, the same as in Diclofenac. For Clarithromycin, the regional interest in England and Wales shows an increase over the examined period, while in Scotland a significant decrease is observed. For Erythromycin, regionally, the only significant increase is observed in England. 
Overall, we observe that Wales shows an increase in online interest in all substances apart from Diclofenac and Erythromycin, while in England, an increase is observed in Diclofenac, Clarithromycin and Erythromycin. In Scotland, the online interest in all substances apart from Diclofenac is decreasing, while in Northern Ireland the only significant change in online interest (increase) is observed in Azithromycin.

\subsection{Total Prescriptions and Costs per Substance}

In Figures 8-11 we present (a) the total number of prescriptions (Pxs) and (b) total cost (Nic) per substance for each of the examined years in England [68], Wales [69], Scotland [70], and Northern Ireland [71], respectively. The detailed data can be found in Appendix B. In England, results revealed a high decrease in Diclofenac's number of issued prescriptions from 2004 to 2014 starting in 2008, Estradiol and Erythromycin show a slight steady decrease in issued prescriptions over the examined period, while Azithromycin and Clarithromycin show a slight increase in issued prescriptions since 2004. The total cost (£) for all substances has overall decreased since 2004, apart from Azithromycin that shows a slight increase in the examined period.

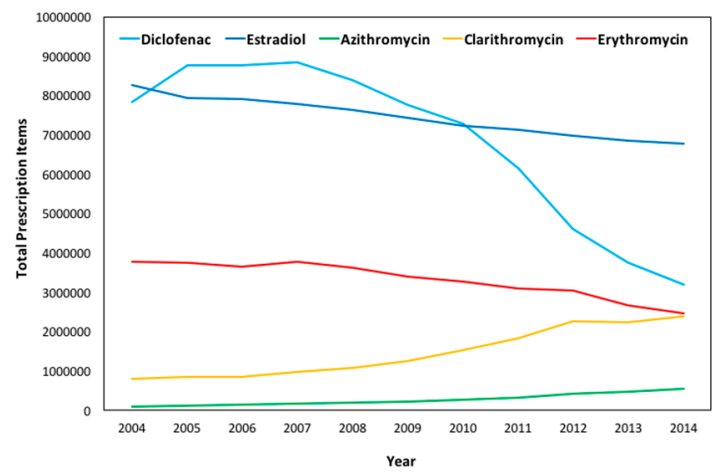

(a)

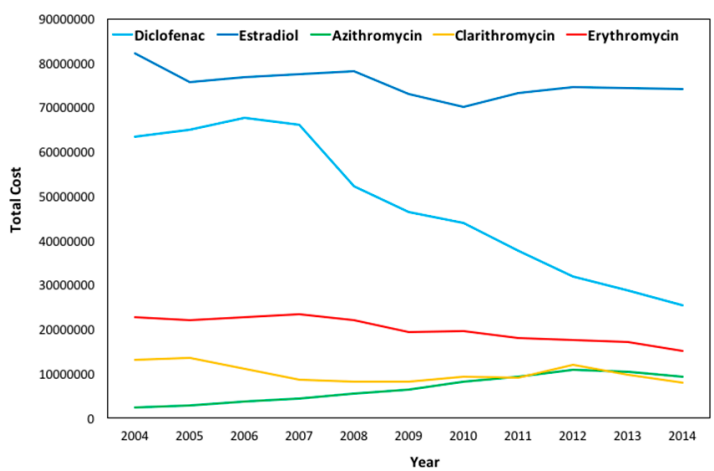

(b)

Figure 8. England's Total (a) Prescription Items and (b) Cost (£) per substance from 2004 to 2014.

In Wales, a high decrease in issued prescriptions in Diclofenac and a significant decrease in Estradiol and Erythromycin are observed, while a slight increase in the number of prescriptions is observed for Clarithromycin and Azithromycin; a pattern similar to that of England. As demonstrated in Figure 9b, the total cost for the substances follows that of the number of prescriptions in Diclofenac, Estradiol, and Erythromycin, while for Azithromycin and Clarithromycin, though prescription items increased, the cost slightly decreased from 2012 to 2014.

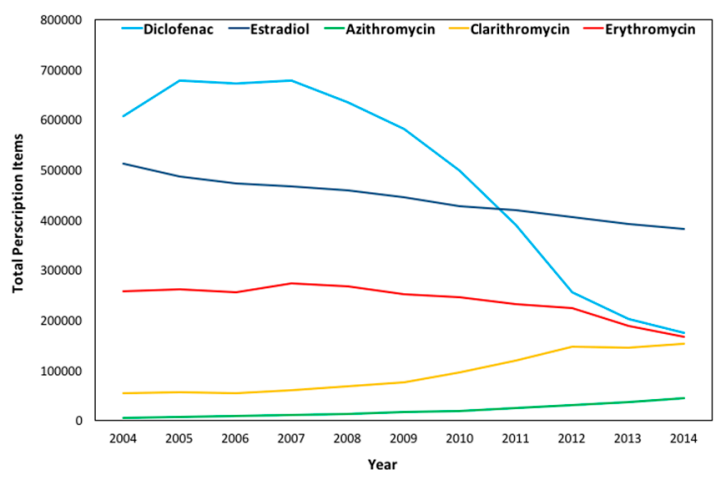

(a)

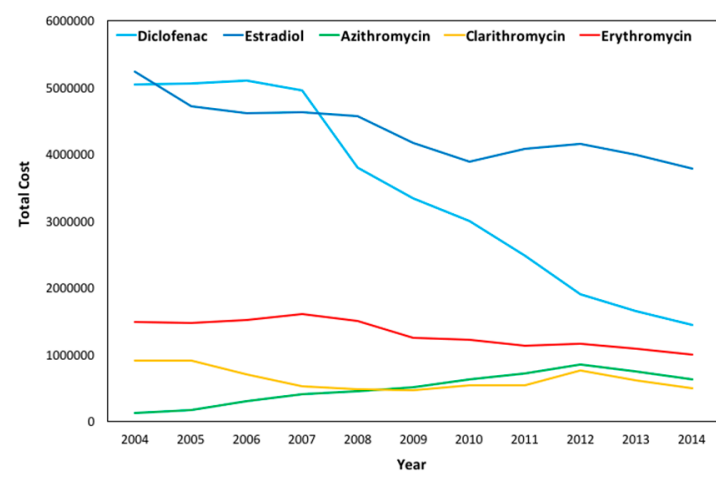

(b)

Figure 9. Wales' Total (a) Prescription Items and (b) Cost (£) per substance from 2004 to 2014. 
In Scotland, the prescriptions in Diclofenac, though increasing from 2004 to 2012, show a sudden decrease from 2012 to 2014, while the total cost shows a significant overall decrease from 2004 to 2014. For Estradiol, both prescriptions issued and total cost show a slight decrease over the examined period, the same as for Erythromycin. For Clarithromycin and Azithromycin, the issued prescriptions show an increase, apart for Clarithromycin from 2013 to 2014. The total cost for Clarithromycin has shown a decrease from 2006 to 2008, and a slight decrease since 2013, while for Azithromycin, the total cost has slightly increased over the examined years.

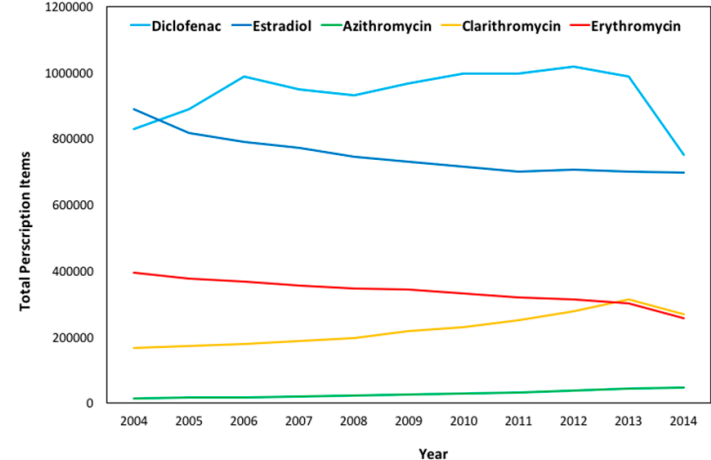

(a)

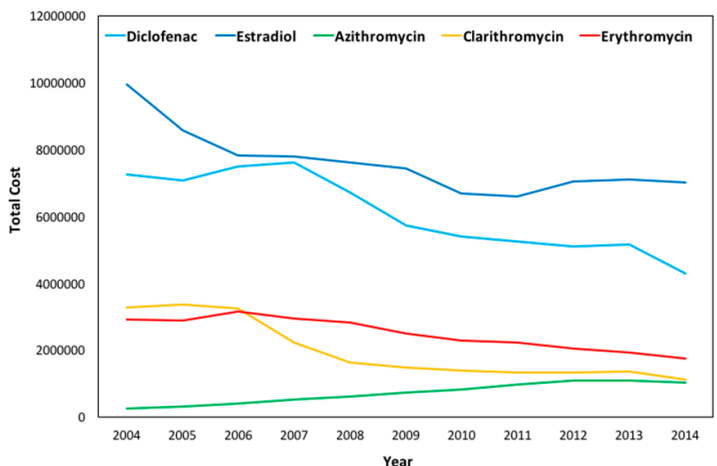

(b)

Figure 10. Scotland's Total (a) Prescription Items and (b) Cost (£) per substance from 2004 to 2014.

In Northern Ireland, as shown in Figure 11, the total prescriptions items for Diclofenac showed a slight increase up to 2010 and decreased significantly until 2014, the same as for the total cost. Estradiol's prescription items and cost are relatively stable throughout the examined period, while Erythromycin slightly decreases in both fields. For Clarithromycin, while the total prescriptions have increased since 2004, the cost shows a slight overall decrease, and for Azithromycin there is a small increase in both total prescriptions and cost over the examined period.

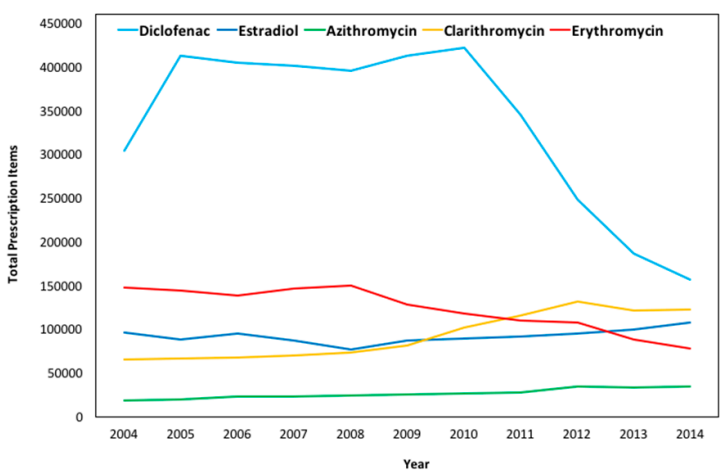

(a)

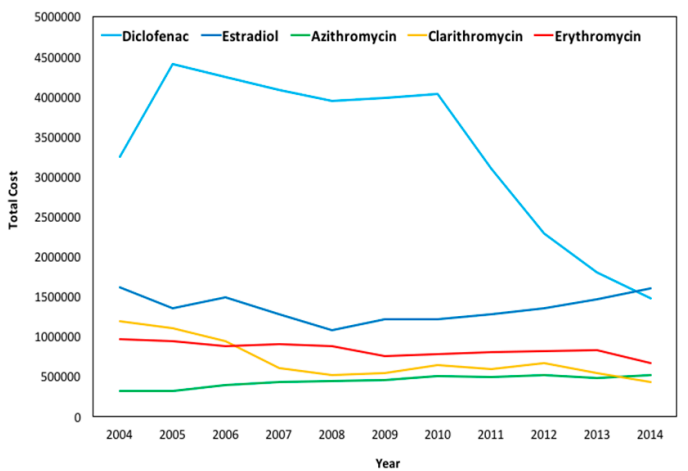

(b)

Figure 11. Northern Ireland's Total (a) Prescription Items and (b) Cost (£) per substance from 2004 to 2014.

Overall, we observe that Diclofenac is the substance with the most significant change out of the examined substances, with both prescription items and total cost from 2004 to 2014 decreasing.

\subsection{Research Interest}

In order to further examine the interest in the five examined micropollutants, we ran searches in the Scopus database [73] consisting of each of the substances' number of documents with the respective term for each year from 2004 to 2014 Worldwide (Table 5). In addition, we further limited the searches in Scopus to include only published papers from 2004 to 2014 with UK affiliation, as shown in Table 6. 
Table 5. Total Scopus Number of Documents with the terms Diclofenac, Estradiol, Azithromycin, Clarithromycin, and Erythromycin from 2004 to 2014.

\begin{tabular}{cccccc}
\hline Year & Diclofenac & Estradiol & Azithromycin & Clarithromycin & Erythromycin \\
\hline 2004 & 1470 & 4203 & 1259 & 1582 & 2537 \\
2005 & 1573 & 4342 & 1320 & 1593 & 2554 \\
2006 & 1561 & 4384 & 1267 & 1445 & 2414 \\
2007 & 1566 & 4278 & 1282 & 1443 & 2391 \\
2008 & 1538 & 4453 & 1242 & 1422 & 2429 \\
2009 & 1659 & 4364 & 1348 & 1493 & 2308 \\
2010 & 1708 & 4376 & 1332 & 1401 & 2215 \\
2011 & 1832 & 4447 & 1358 & 1334 & 2126 \\
2012 & 1896 & 4507 & 1486 & 1356 & 2202 \\
2013 & 1899 & 4469 & 1700 & 1465 & 2259 \\
2014 & 1714 & 4316 & 1513 & 1249 & 2005 \\
Total & 18,416 & 48,139 & 15,107 & 15,783 & 25,440 \\
\hline
\end{tabular}

Table 6. Scopus Number of Documents with UK Affiliation with the terms Diclofenac, Estradiol, Azithromycin, Clarithromycin, and Erythromycin from 2004 to 2014.

\begin{tabular}{cccccc}
\hline Year & Diclofenac & Estradiol & Azithromycin & Clarithromycin & Erythromycin \\
\hline 2004 & 147 & 244 & 96 & 97 & 233 \\
2005 & 160 & 253 & 105 & 112 & 229 \\
2006 & 163 & 256 & 93 & 74 & 220 \\
2007 & 157 & 233 & 83 & 97 & 216 \\
2008 & 166 & 263 & 92 & 112 & 217 \\
2009 & 137 & 251 & 108 & 123 & 209 \\
2010 & 121 & 244 & 132 & 104 & 182 \\
2011 & 156 & 220 & 107 & 121 & 160 \\
2012 & 133 & 205 & 116 & 115 & 161 \\
2013 & 134 & 242 & 147 & 125 & 140 \\
2014 & 108 & 188 & 129 & 98 & 117 \\
Total & 1582 & 2599 & 1208 & 1178 & 2084 \\
\hline
\end{tabular}

We observe that the order of the substances in terms of published papers is Estradiol, Erythromycin, Diclofenac, Clarithromycin, and Azithromycin, are at no point similar to the Worldwide Google hits for the terms from 2004 to 2014 . This shows that the scientific community and the public view these terms differently.

We observe that the number of published papers in Scopus with a UK affiliation is the highest for Estradiol, followed by Erythromycin, Diclofenac, Azithromycin, and Clarithromycin in that order. Thus we conclude that the scientific interest in the UK follows the Worldwide one.

\subsection{Correlations amongst Prescription, Google Hits, and Scientific Papers}

Table 7 consists of the Pearson correlations for the five examined substances between the percentized prescriptions (Pxs) and Google Trends (GT) percentized data in the UK, England, Wales, Scotland, and Northern Ireland, and between the Scopus' percentized number of documents and Google Trends hits in the UK and Worldwide.

As indicated by the results, prescription items and Google hits in the UK are highly correlated for Diclofenac, Azithromycin, and Clarithromycin, while no correlation whatsoever is observed for Estradiol. Correlations with high statistical significance $(p<0.01)$ are also observed in prescription items and Google hits in England in Diclofenac and Clarithromycin, in prescription items and Google hits in Wales in Clarithromycin, in the Scopus documents and Google hits for all substances Worldwide apart from Estradiol, and in the Scopus documents and Google hits in the UK in Azithromycin. Another interesting observation is that population seems to play a significant role in the regional results. For example, as shown in Table 7, for Diclofenac, though in the respective regions the correlations 
between Google hits and prescriptions vary from high to none, in the UK as a total they exhibit a high correlation, the same as for Clarithromycin and Azithromycin, while, for Erythromycin in Wales, there is a weak negative correlation.

Table 7. Correlations amongst Prescriptions, Google Hits and Published Scientific Papers for Diclofenac, Estradiol, Azithromycin, Clarithromycin, and Erythromycin.

\begin{tabular}{|c|c|c|c|c|c|c|c|}
\hline Substance & $\begin{array}{l}\text { Pxs-GT } \\
\text { (UK) }\end{array}$ & $\begin{array}{c}\text { Pxs-GT } \\
\text { (England) }\end{array}$ & $\begin{array}{c}\text { Pxs-GT } \\
\text { (Scotland) }\end{array}$ & $\begin{array}{l}\text { Pxs-GT } \\
\text { (Wales) }\end{array}$ & $\begin{array}{c}\text { Pxs-GT } \\
\text { (N. Ireland) }\end{array}$ & $\begin{array}{c}\text { Scopus-GT } \\
\text { (Worldwide) }\end{array}$ & $\begin{array}{l}\text { Scopus-GT } \\
\text { (UK) }\end{array}$ \\
\hline Diclofenac & $0.7814^{* * *}$ & $0.7903^{* * *}$ & 0.1358 & $0.6045^{* *}$ & 0.5843 * & $0.8637^{* * * *}$ & 0.3067 \\
\hline Estradiol & -0.2775 & -0.3455 & 0.0369 & 0.4974 & 0.5189 & -0.5293 & 0.371 \\
\hline Azithromycin & $0.8287 * * *$ & $0.6395^{* *}$ & -0.0642 & $0.7133^{* *}$ & 0.5783 * & $-0.7569^{* * *}$ & $0.7778^{* * *}$ \\
\hline Clarithromycin & $0.9531^{* * * *}$ & $0.9384^{* * * *}$ & 0.4014 & $0.7535^{* * *}$ & 0.4935 & $-0.9129 * * * *$ & $0.6631^{* *}$ \\
\hline Erythromycin & $0.5677 *$ & 0.1295 & $0.7795^{* * *}$ & $-0.5847^{*}$ & 0.3736 & $-0.7933^{* * *}$ & $0.609^{* *}$ \\
\hline
\end{tabular}

\section{Discussion}

Since 2004, there have been many studies that examined the micropollutants' occurrence and removal [16], in addition to their effects on environmental and human health. Out of the EU watchlist, the substances that have been studied the most are Diclofenac, Azithromycin, Clarithromycin, Erythromycin, Estradiol, and Estrone, contrary to the rest of the list, where the substances have not been extensively studied [16]. In the UK, comparing the examined substances, the results indicated that the online interest is mainly focused on Diclofenac, however, that interest has showed a slight decrease from 2004 to 2014. In contrast, the online interest in the Macrolide Antibiotics, specifically Clarithromycin and Azithromycin on a lower level, has showed a significant increase, whereas Erythromycin is the most searched for Macrolide, with its online interest maintained at similar levels throughout the years 2004-2014 compared to other substances. The online interest in Estradiol has remained at low levels throughout these 11 years.

The declining online interest and prescribing of Diclofenac follows the results of a Europe-wide review regarding its cardiovascular complications, which led to the MHRA adding Diclofenac to the prescription-only-medication list in 2015 [72]. The MHRA suggests that Naproxen and low dose Ibuprofen can be used instead, as they have a safer cardiovascular profile [74]. However, Naproxen and Ibuprofen have been shown to accumulate in fish bile, as does Diclofenac [75]. Therefore, despite them having a better side effect profile for human use, they have the potential to cause harm to the aquatic environment.

The changes in the online interest and prescribing patterns of the Macrolide Antibiotics are due to various reasons. Initially Erythromycin was the most widely prescribed Macrolide, however during the course of these 10 years, Clarithromycin has gained ground over Erythromycin. This is justified by changes in the guidelines, which now state that Clarithromycin is the Macrolide of choice, as it has an improved side-effect profile and better patient compliance due to a less frequent dosage regiment [76]. Azithromycin ensures the maximum patient compliance by only requiring a once a day dosing for 3 days [29] and causing fewer interactions with other medications [32]. However, due to having a longer half-life than the rest, it provides a greater opportunity for resistance to develop, which could be an explanation on why it is not the Macrolide of choice in penicillin allergy [76]. Azithromycin is most commonly used for the treatment of sexually transmitted diseases, such as chlamydia and gonorrhea. The increase in Azithromycin prescribing can be linked to the increased rate of chlamydia and gonorrhea diagnosis during the past 10 years [77]. In addition, due to its anti-inflammatory action, it is also used in patients with deteriorating cystic fibrosis as part of an off-label 6-month treatment course [78]. In order to minimize the negative impact of Macrolide use to both humans and the aquatic environment, it is important to control their prescribing and use for farming purposes. The National institute for Health and Care Excellence has implemented certain guidelines in order to ensure the optimum use of antibiotics, also suggesting the minimum antibiotic prescribing in farming $[79,80]$. 
Estradiol has shown a rather minor online interest, compared to other substances; however, it is one of the most commonly prescribed substances out of those investigated. This is justified, as the Estradiol data work as an umbrella term covering both Estradiol and Ethinylestradiol prescribing data. Estradiol is mostly used in hormone replacement therapies in post-menopausal women as well as in conditions such as female hypogonadism and primary ovarian therapy. Ethinylestradiol is used in contraceptive pills and in emergency hormonal contraception, as well as in hormone replacement therapies and female hypogonadism [26]. The vast usage of these two substances can partially justify the increased research interest in Estradiol. It must be noted, that Estradiol, containing preparations such as contraceptive pills containing 17- $\alpha$-ethinylestradiol, can be obtained from sexual health clinics without a prescription [81], and thus would not appear in the data analyzed by this study, which could be explaining why Estradiol is the only substance not to exhibit any correlation with Google hits in any region.

Though Diclofenac prescriptions have decreased over the past years, it is still a widely prescribed item (see Appendix B), that can cause environmental complications despite wastewater treatment. Diclofenac's removal through conventional wastewater treatment varies from $0 \%$ to $80 \%$ [18], and, as it is not always absorbed onto organic matter [20], it is detected in the aquatic environment $[18,19]$ and in the tap water in EU countries [20]. This also applies to the Macrolide Antibiotics, where concerns are being raised on their effect on environmental and human health due to them not being completely removed through conventional treatment [25]. It has been shown that their detection in wastewater adds to the increased antimicrobial resistance, as well as toxicity due to Clarithromycin and Erythromycin. Estradiol is also not fully degraded, and its presence in surface waters [39] affects sea life [41]. As wastewater treatment is suggested to not completely remove the concentrations of these substances in the aquatic environment [14,16-18,39], the solution could be to manage the pollution at the source, which is the human, veterinarian, and agricultural intake and use. Steps towards this direction have been implemented, as for example in the case of Diclofenac, which is now a prescription-only drug in the UK [72].

This study, like any other study, has some limitations. At first, the analysis only takes into account the online interest of these substances in the UK, which could, however, provide ground for future research on the topic in other EU countries. In addition, the substances examined are limited to five, though this methodology can be applied in other substances included in the watchlist when more research has been documented. Furthermore, not each hit corresponds to only prescription issuing, as many of them could be for educational/academic searches or general interest on the subject, all the while not taking into account searches that are related to prescription issuing, e.g., due to incorrect spelling. Despite that, Google Trends' data have been suggested to be accurate for analyzing human behavior, which is further supported by previous studies indicating that Google Trends can indeed be a valid predictor of human behavior. In this study, it is observed that search queries are strongly correlated with three of the five substances' prescription volumes, further supported by the no observed correlation in Estradiol, which, as mentioned above, can be obtained directly through sex clinics. Nevertheless, as is presented by the correlations in Section 3 between the prescriptions issued and the hits in Google in the UK, we argue that the analysis of the online interest in micropollutants can assist with the prediction of the public's intake of these substances, in order to evaluate the steps that need to be taken towards the direction of decreasing these substances' use. In addition, as the amount of antibiotics found in wastewater is proportional to the prescribing trends of each country [34], the forecasting and monitoring of their concentrations in the aquatic environment is possible.

\section{Conclusions}

Given the increased interest in several micropollutants in the EU, and as they have been suggested to be possibly harmful for environmental and human health, their monitoring in the aquatic environment has been implemented with Decision 2015/495. This study analyzed the changes in online search queries, in order to examine how Google Trends' data can be used to evaluate the 
public's interest in relation to the use of these drugs in the UK. Google Trends, being all the more used for examining the changes in interest in various medical, health, and environment-related terms, is a valid tool for evaluating online interest, as it uses the revealed and not the stated preferences of the users.

Normalized data from Google Trends were used in this study to examine the change in UK's online interest in Diclofenac, Estradiol, Azithromycin, Clarithromycin, and Erythromycin, included in the EU watchlist, from 2004 to 2014, the correlations between the public's interest and the prescriptions issued for these substances over the examined period, and the scientific interest in terms of published papers. Though it could not be argued that each search query corresponds to the respective prescription issuing, with any potential bias this may include, the results by the presented empirical relationships indicate that there indeed exists a strong correlation between prescription items and Google hits in the UK for Diclofenac, Azithromycin, and Clarithromycin, and a weak correlation for Erythromycin, while for Estradiol no correlation in any region is observed. The interest in Diclofenac is high, though declining, Estradiol exhibits lower and declining interest, while high but stable interest in observed for Erythromycin. Azithromycin and Clarithromycin, though searched for less, show a significant increase in online interest over the examined period. Estradiol's online interest is in contrast to the issued prescriptions, though, interestingly, it is the most popular out of the five examined substances in terms of scientific publications.

Further research could include more case studies of EU countries, and to also compare different states in terms of interest and Health Care System's performance. Furthermore, the possibility of exploring the relationship between online search queries from Google and concentrations of these substances in the aquatic environment could be examined, so as to develop an algorithm for forecasting these concentrations, and, subsequently, better monitor the degradation observed in the aquatic environment.

Acknowledgments: The funds for covering the costs to publish in open access were received from the Special Research Account of Democritus University of Thrace, Project Number 60050.

Author Contributions: Amaryllis Mavragani and Konstantinos P. Tsagarakis conceived and designed the research; Alexia Sampri collected the data, Amaryllis Mavragani and Konstantinos P. Tsagarakis analyzed the data; Amaryllis Mavragani, Karla Sypsa, and Konstantinos P. Tsagarakis wrote the paper.

Conflicts of Interest: The authors declare no conflict of interest.

\section{Appendix A}

Table A1 consists of the yearly averages of the percentized hits for the terms 'Diclofenac' (D), 'Estradiol' (ES), 'Azithromycin' (A), 'Clarithromycin' (C), and 'Erythromycin' (E) in England, Wales, Scotland, and Northern Ireland from 2004 to 2014.

Table A1. Yearly Averages of the Percentized Hits in Diclofenac, Estradiol, Azithromycin, Clarithromycin, and Erythromycin in England, Wales, Scotland \& Northern Ireland, 2004-2014.

\begin{tabular}{|c|c|c|c|c|c|c|c|c|c|c|}
\hline \multirow{2}{*}{ Year } & \multicolumn{5}{|c|}{ England } & \multicolumn{5}{|c|}{ Wales } \\
\hline & D & ES & A & $\mathrm{C}$ & E & D & ES & A & C & E \\
\hline 2004 & $42.22 \%$ & $11.40 \%$ & $10.99 \%$ & $10.61 \%$ & $24.78 \%$ & $58.46 \%$ & $3.73 \%$ & $0.00 \%$ & $3.62 \%$ & $34.19 \%$ \\
\hline 2005 & $45.53 \%$ & $8.03 \%$ & $8.67 \%$ & $8.82 \%$ & $28.95 \%$ & $39.26 \%$ & $6.03 \%$ & $3.09 \%$ & $0.00 \%$ & $51.62 \%$ \\
\hline 2006 & $49.84 \%$ & $6.84 \%$ & $7.20 \%$ & $7.07 \%$ & $29.06 \%$ & $61.19 \%$ & $5.06 \%$ & $4.88 \%$ & $0.00 \%$ & $28.86 \%$ \\
\hline 2007 & $51.67 \%$ & $5.57 \%$ & $7.52 \%$ & $7.09 \%$ & $28.15 \%$ & $44.28 \%$ & $1.48 \%$ & $10.53 \%$ & $10.04 \%$ & $33.66 \%$ \\
\hline 2008 & $50.09 \%$ & $6.68 \%$ & $8.19 \%$ & $7.55 \%$ & $27.49 \%$ & $31.47 \%$ & $9.21 \%$ & $9.51 \%$ & $16.08 \%$ & $33.74 \%$ \\
\hline 2009 & $50.32 \%$ & $8.12 \%$ & $8.25 \%$ & $8.77 \%$ & $24.55 \%$ & $28.42 \%$ & $11.74 \%$ & $14.11 \%$ & $19.53 \%$ & $26.20 \%$ \\
\hline 2010 & $50.21 \%$ & $8.27 \%$ & $8.37 \%$ & $10.05 \%$ & $23.09 \%$ & $30.93 \%$ & $10.92 \%$ & $16.72 \%$ & $14.35 \%$ & $27.08 \%$ \\
\hline 2011 & $48.70 \%$ & $4.48 \%$ & $8.54 \%$ & $12.00 \%$ & $26.28 \%$ & $34.21 \%$ & $10.85 \%$ & $14.30 \%$ & $17.88 \%$ & $22.77 \%$ \\
\hline 2012 & $43.78 \%$ & $4.30 \%$ & $9.49 \%$ & $16.18 \%$ & $26.26 \%$ & $28.09 \%$ & $11.70 \%$ & $17.30 \%$ & $19.12 \%$ & $23.80 \%$ \\
\hline 2013 & $42.44 \%$ & $4.58 \%$ & $10.22 \%$ & $17.15 \%$ & $25.61 \%$ & $31.36 \%$ & $10.04 \%$ & $14.34 \%$ & $19.00 \%$ & $25.27 \%$ \\
\hline 2014 & $33.93 \%$ & $5.16 \%$ & $11.84 \%$ & $22.17 \%$ & $26.90 \%$ & $22.53 \%$ & $12.12 \%$ & $16.55 \%$ & $23.55 \%$ & $25.26 \%$ \\
\hline
\end{tabular}


Table A1. Cont.

\begin{tabular}{|c|c|c|c|c|c|c|c|c|c|c|}
\hline \multirow{2}{*}{ Year } & \multicolumn{5}{|c|}{ Scotland } & \multicolumn{5}{|c|}{ Northern Ireland } \\
\hline & D & ES & A & $\mathrm{C}$ & E & D & ES & A & $\mathrm{C}$ & $\mathbf{E}$ \\
\hline 2004 & $38.55 \%$ & $9.88 \%$ & $9.32 \%$ & $12.91 \%$ & $29.34 \%$ & $25.36 \%$ & $20.93 \%$ & $0.00 \%$ & $31.46 \%$ & $22.25 \%$ \\
\hline 2005 & $40.00 \%$ & $5.84 \%$ & $8.32 \%$ & $9.26 \%$ & $36.58 \%$ & $24.53 \%$ & $8.26 \%$ & $15.78 \%$ & $8.26 \%$ & $43.17 \%$ \\
\hline 2006 & $33.02 \%$ & $12.69 \%$ & $11.26 \%$ & $17.21 \%$ & $25.82 \%$ & $50.27 \%$ & $10.11 \%$ & $14.55 \%$ & $4.23 \%$ & $20.83 \%$ \\
\hline 2007 & $30.86 \%$ & $13.78 \%$ & $14.13 \%$ & $17.78 \%$ & $23.45 \%$ & $53.65 \%$ & $8.12 \%$ & $9.07 \%$ & $6.63 \%$ & $22.53 \%$ \\
\hline 2008 & $34.00 \%$ & $14.39 \%$ & $13.50 \%$ & $15.72 \%$ & $22.39 \%$ & $37.28 \%$ & $6.20 \%$ & $6.20 \%$ & $19.02 \%$ & $31.29 \%$ \\
\hline 2009 & $34.53 \%$ & $15.47 \%$ & $13.52 \%$ & $15.44 \%$ & $21.05 \%$ & $40.78 \%$ & $9.41 \%$ & $12.11 \%$ & $11.25 \%$ & $26.45 \%$ \\
\hline 2010 & $37.93 \%$ & $11.42 \%$ & $14.34 \%$ & $15.80 \%$ & $20.51 \%$ & $43.88 \%$ & $9.33 \%$ & $9.16 \%$ & $18.33 \%$ & $19.29 \%$ \\
\hline 2011 & $49.15 \%$ & $8.73 \%$ & $9.15 \%$ & $13.00 \%$ & $19.97 \%$ & $31.57 \%$ & $12.58 \%$ & $17.00 \%$ & $18.65 \%$ & $20.21 \%$ \\
\hline 2012 & $47.97 \%$ & $7.56 \%$ & $9.21 \%$ & $16.02 \%$ & $19.25 \%$ & $30.48 \%$ & $11.52 \%$ & $16.67 \%$ & $20.76 \%$ & $20.57 \%$ \\
\hline 2013 & $48.72 \%$ & $5.64 \%$ & $10.34 \%$ & $15.33 \%$ & $19.97 \%$ & $29.65 \%$ & $11.51 \%$ & $16.51 \%$ & $21.16 \%$ & $21.16 \%$ \\
\hline 2014 & $41.52 \%$ & $6.75 \%$ & $11.07 \%$ & $19.57 \%$ & $21.10 \%$ & $24.47 \%$ & $13.43 \%$ & $17.82 \%$ & $23.21 \%$ & $21.08 \%$ \\
\hline
\end{tabular}

\section{Appendix B}

Tables B1-B4 consist of the total prescriptions issued and total cost per substance in England [68], Wales [69], Scotland [70], and Northern Ireland [71], respectively.

Table B1. Total Prescriptions Items and Total Cost per each Examined Substance from 2004 to 2014 in England.

\begin{tabular}{|c|c|c|c|c|c|c|c|c|c|c|}
\hline \multirow{2}{*}{ Year } & \multicolumn{2}{|c|}{ Diclofenac } & \multicolumn{2}{|c|}{ Estradiol } & \multicolumn{2}{|c|}{ Azithromycin } & \multicolumn{2}{|c|}{ Clarithromycin } & \multicolumn{2}{|c|}{ Erythromycin } \\
\hline & Pxs & $\mathrm{Nic}$ & Pxs & $\mathrm{Nic}$ & Pxs & $\mathrm{Nic}$ & Pxs & $\mathrm{Nic}$ & Pxs & Nic \\
\hline 2004 & $7,835,083$ & $63,478,356$ & $8,251,847$ & $82,173,534$ & 103,963 & $2,362,482$ & 795,270 & $13,225,502$ & $3,766,953$ & $22,679,369$ \\
\hline 2006 & $8,764,671$ & $67,572,195$ & $7,899,767$ & $76,832,218$ & 139,963 & $3,652,018$ & 853,852 & $11,156,286$ & $3,646,943$ & $22,700,296$ \\
\hline 2007 & $8,851,377$ & $66,137,104$ & $7,772,486$ & $77,574,221$ & 164,441 & $4,498,897$ & 973,997 & $8,723,270$ & $3,763,697$ & $23,421,676$ \\
\hline 2008 & $8,388,693$ & $52,224,959$ & $7,642,773$ & $78,099,605$ & 191,842 & $5,446,935$ & $1,077,097$ & $8,294,989$ & $3,630,628$ & $22,108,822$ \\
\hline 2011 & $6,145,755$ & $37,721,617$ & $7,129,956$ & $73,214,245$ & 326,009 & $9,429,128$ & $1,823,774$ & $9,077,182$ & $3,098,773$ & $17,956,893$ \\
\hline 2012 & $4,595,666$ & $31,811,877$ & $6,983,092$ & $74,604,834$ & 410,781 & $10,998,016$ & $2,258,788$ & $12,040,359$ & $3,050,915$ & $17,696,503$ \\
\hline 2013 & $3,742,673$ & $28,798,913$ & $6,841,917$ & $74,364,235$ & 476,529 & $10,369,500$ & $2,245,430$ & $9,833,664$ & $2,673,169$ & $17,052,495$ \\
\hline 2014 & $3,191,910$ & $25,334,219$ & $6,767,640$ & $74,071,656$ & 543,986 & $9,296,368$ & $2,397,752$ & $8,030,665$ & $2,451,888$ & $15,181,583$ \\
\hline
\end{tabular}

Table B2. Total Prescriptions Items and Total Cost per each Examined Substance from 2004 to 2014 in Wales.

\begin{tabular}{|c|c|c|c|c|c|c|c|c|c|c|}
\hline \multirow{2}{*}{ Year } & \multicolumn{2}{|c|}{ Diclofenac } & \multicolumn{2}{|c|}{ Estradiol } & \multicolumn{2}{|c|}{ Azithromycin } & \multicolumn{2}{|c|}{ Clarithromycin } & \multicolumn{2}{|c|}{ Erythromycin } \\
\hline & Pxs & Nic & Pxs & Nic & Pxs & Nic & Pxs & Nic & Pxs & Nic \\
\hline 2004 & 607,248 & $5,042,779$ & 1,028 & J,200,012 & 4568 & 117,091 & 53,652 & 903,849 & 256,824 & $1,481,228$ \\
\hline 2005 & 678,484 & $5,046,112$ & 485,694 & $4,716,870$ & 5699 & 172,899 & 55,902 & 900,822 & 261,533 & $1,469,651$ \\
\hline 2006 & 671,812 & $5,093,644$ & 472,642 & $4,613,931$ & 7941 & 294,818 & 53,439 & 698,619 & 255,790 & $1,519,369$ \\
\hline 2007 & 678,105 & $1,067,870$ & 466,309 & 4,617, & 10,364 & 55 & 60,2 & 521 & 272,313 & $1,600,360$ \\
\hline 2008 & 635,085 & $3,793,644$ & 459, & 4,569 & 12, & 455,641 & 67,3 & 478, & 266,925 & $1,504,670$ \\
\hline 2009 & 580,770 & $3,338,177$ & 443,828 & $4,163,532$ & 15,805 & 511,380 & 75,638 & 460,939 & 251,236 & $1,249,129$ \\
\hline 2010 & 498,367 & $2,989,491$ & 427,581 & $3,883,315$ & 19,028 & 620,973 & 94,390 & 530,313 & 245,055 & $1,215,885$ \\
\hline 2011 & 388,495 & $2,472,713$ & 419,273 & $4,080,473$ & 24,305 & 719,482 & 119,245 & 539,206 & 230,841 & $1,133,924$ \\
\hline 2012 & 254,997 & $1,901,062$ & 404,993 & $4,145,176$ & 30,320 & 843,584 & 146,134 & 764,544 & 222,667 & $1,159,973$ \\
\hline 2013 & 201,798 & $1,647,361$ & 390,974 & $3,984,881$ & 36,997 & 743,283 & 145,506 & 610,597 & 188,956 & $1,092,414$ \\
\hline 2014 & 173,686 & $1,440,695$ & 381,413 & $3,781,056$ & 44,190 & 633,734 & 153,445 & 495,161 & 166,866 & 994,933 \\
\hline
\end{tabular}


Table B3. Total Prescriptions Items and Total Cost per each Examined Substance from 2004 to 2014 in Scotland.

\begin{tabular}{|c|c|c|c|c|c|c|c|c|c|c|}
\hline \multirow{2}{*}{ Year } & \multicolumn{2}{|c|}{ Diclofenac } & \multicolumn{2}{|c|}{ Estradiol } & \multicolumn{2}{|c|}{ Azithromycin } & \multicolumn{2}{|c|}{ Clarithromycin } & \multicolumn{2}{|c|}{ Erythromycin } \\
\hline & Pxs & Nic & Pxs & Nic & Pxs & Nic & Pxs & Nic & Pxs & Nic \\
\hline 2004 & 828,315 & $7,240,001$ & 888,889 & $9,945,074$ & 13,510 & 251,295 & 165,909 & $3,276,480$ & 392,270 & 895,902 \\
\hline 2005 & 888 & 7,064 & 816,091 & 8,5 & 14 & 12 & 58 & 31 & 375,763 & 755 \\
\hline 2006 & 988,181 & $7,488,5$ & 790,058 & 7,825, & 16,7 & 38 & 177 & 3229 & 366,113 & $3,149,333$ \\
\hline 2007 & 947,237 & $7,598,272$ & 769,913 & $7,790,662$ & 19,231 & 512 & 186,086 & $2,234,031$ & 355,662 & $2,932,906$ \\
\hline 2008 & 930,227 & $6,706,394$ & 743,438 & $7,590,806$ & 21,053 & 595,080 & 197,300 & $1,621,024$ & 346,642 & $2,821,866$ \\
\hline 2009 & 966,564 & $5,709,160$ & 729,726 & $7,412,799$ & 25,109 & 729,715 & 215,696 & $1,483,031$ & 341,418 & $2,483,633$ \\
\hline 2010 & 996,611 & $5,400,387$ & 712,913 & $6,688,184$ & 28,035 & 818,739 & 229,736 & $1,371,893$ & 329,611 & $2,278,828$ \\
\hline 2011 & 996,967 & $5,231,754$ & 698,473 & $6,582,956$ & 31,215 & 956,196 & 250,527 & $1,336,948$ & 317,831 & $2,223,376$ \\
\hline 2012 & $1,016,319$ & $5,097,518$ & 705,705 & $7,048,774$ & 36,229 & $1,098,991$ & 275,497 & $1,330,449$ & 313,722 & $2,041,729$ \\
\hline 2013 & 986,949 & $5,156,256$ & 700,361 & $7,092,274$ & 41,638 & $1,090,442$ & 313,086 & $1,341,904$ & 301,406 & $1,937,615$ \\
\hline 2014 & 750,888 & $4,298,521$ & 694,916 & $7,011,775$ & 44,818 & $1,039,360$ & 266,637 & $1,121,077$ & 255,645 & $1,736,324$ \\
\hline
\end{tabular}

Table B4. Total Prescriptions Items and Total Cost per each Examined Substance from 2004 to 2014 in Northern Ireland.

\begin{tabular}{|c|c|c|c|c|c|c|c|c|c|c|}
\hline \multirow{2}{*}{ Year } & \multicolumn{2}{|c|}{ Diclofenac } & \multicolumn{2}{|c|}{ Estradiol } & \multicolumn{2}{|c|}{ Azithromycin } & \multicolumn{2}{|c|}{ Clarithromycin } & \multicolumn{2}{|c|}{ Erythromycin } \\
\hline & Pxs & Nic & Pxs & Nic & Pxs & Nic & Pxs & Nic & Pxs & Nic \\
\hline 2004 & 303,754 & $3,243,777$ & 96,509 & $1,617,714$ & 18,353 & 321,834 & 65,089 & $1,197,697$ & 147,641 & 969,240 \\
\hline 2005 & 412,903 & $4,402,937$ & 88,408 & $1,351,945$ & 19,548 & 321,170 & 66,880 & $1,107,689$ & 143,967 & 936,716 \\
\hline 2006 & 404,206 & $4,241,150$ & 94,915 & $1,491,020$ & 22,380 & 392,940 & 67,440 & 940,586 & 137,832 & 874,958 \\
\hline 2007 & 401,661 & $4,081,595$ & 86,548 & $1,276,070$ & 23,380 & 435,724 & 70,131 & 607,166 & 146,797 & 898,771 \\
\hline 2008 & 394,935 & $3,949,307$ & 77,148 & $1,084,687$ & 24,536 & 442,670 & 72,918 & 520,957 & 150,073 & 884,860 \\
\hline 2009 & 413,144 & $3,981,120$ & 86,468 & $1,219,970$ & 25,491 & 460,367 & 81,595 & 541,349 & 128,384 & 754,316 \\
\hline 2010 & 421,552 & $4,036,778$ & 89,379 & $1,214,298$ & 26,312 & 499,738 & 101,820 & 645,725 & 117,861 & 778,011 \\
\hline 2011 & 345,627 & $3,102,062$ & 91,519 & $1,276,442$ & 27,760 & 493,735 & 115,077 & 593,917 & 109,444 & 806,347 \\
\hline 2012 & 247,985 & $2,289,123$ & 94,837 & $1,349,398$ & 34,649 & 522,087 & 131,903 & 667,656 & 107,395 & 814,308 \\
\hline 2013 & 186,076 & $1,799,736$ & 99,058 & $1,463,963$ & 32,788 & 479,013 & 120,734 & 545,088 & 88,419 & 829,671 \\
\hline 2014 & 156,732 & $1,477,050$ & 107,500 & $1,602,230$ & 33,831 & 517,421 & 122,544 & 433,467 & 78,104 & 668,663 \\
\hline
\end{tabular}

\section{References}

1. Directive 2000/60/EC of the European Parliament and of the Council of 23 October 2000. Available online: http:/ /ec.europa.eu/health/endocrine_disruptors/docs/wfd_200060ec_directive_en.pdf (accessed on 2 May 2016).

2. Directive 2008/105/EC of the European Parliament and of the Council of 16 December 2008. Available online: http:/ / eur-lex.europa.eu/LexUriServ/LexUriServ.do?uri=OJ:L:2008:348:0084:0097:en:PDF (accessed on 2 May 2016).

3. Directive 2013/39/EU of the European Parliament and of the Council of 12 August 2013. Available online: http:/ / data.europa.eu/eli/dir/2013/39/oj (accessed on 2 May 2016).

4. Decision 2015/495/EU. Available online: http://eur-lex.europa.eu/legal-content/EN/TXT/PDF/?uri= uriserv:OJ.L_.2015.078.01.0040.01.ENG (accessed on 18 July 2016).

5. Mayo Clinic. Drugs and Supplements, Diclofenac (Oral Route). Available online: http://www.mayoclinic. org/drugs-supplements/diclofenac-oral-route/description/drg-20069748 (accessed on 18 July 2016).

6. Duong, M.; Salvo, F.; Pariente, A.; Abouelfath, A.; Lassalle, R.; Droz, C.; Blin, P.; Moore, N. Usage Patterns of 'Over-The-Counter' vs. Prescription-Strength Nonsteroidal Anti-Inflammatory Drugs in France. Br. J. Pharmacol. 2014, 77, 887-895. [CrossRef] [PubMed]

7. Reddy, K.S.; Roy, A. Cardiovascular Risk of NSAIDs: Time to Translate Knowledge into Practice. PLoS Med. 2013, 10, e1001389. [CrossRef] [PubMed]

8. Harirforoosh, S.; Asghar, W.; Jamali, F. Adverse Effects of Nonsteroidal Antiinflammatory Drugs: An Update of Gastrointestinal, Cardiovascular and Renal Complications. J. Pharm. Pharm. Sci. 2013, 16, 821-847. [CrossRef] [PubMed] 
9. Medicines and Healthcare products Regulatory Agency (MHRA). Non-Steroidal Anti-Inflammatory Drugs and Cardiovascular Risks in the General Population; MHRA: London, UK, 2010. Available online: http:/ /www.mhra. gov.uk/home/groups/s-par/documents/websiteresources/con068576.pdf (accessed on 6 August 2016).

10. Sukkar, E. Risk of Heart Problems Prompts Removal of OTC Diclofenac from UK Pharmacy Selves. Pharm. J. 2015, 294, 7846. [CrossRef]

11. McGettigan, P.; Henry, D. Use of Non-Steroidal Anti-Inflammatory Drugs that Elevate Cardiovascular Risk: An Examination of Sales and Essential Medicines Lists in Low-, Middle-, and High-Income Countries. PLoS Med. 2013, 10, e1001388. [CrossRef] [PubMed]

12. European Medicines Agency (EMEA). Diclofenac Summary Report; The European Agency for the Evaluation of Medicinal Products Veterinary Medicines and Inspections: London, UK, 2003.

13. Pharmaceutical Press. Clarke's Analysis of Drugs and Poisons; Pharmaceutical Press: London, UK, 2011.

14. Vieno, N.; Sillanpää, M. Fate of Diclofenac in Municipal Wastewater treatment Plant-A Review. Environ. Int. 2014, 69, 28-39. [CrossRef] [PubMed]

15. Khetan, S.K.; Collins, T.J. Human Pharmaceuticals in the Aquatic Environment: A Challenge to Green Chemistry. Chem. Rev. 2007, 107, 2319-2364. [CrossRef] [PubMed]

16. Barbosa, M.O.; Moreira, N.F.F.; Ribeiro, A.R.; Pereira, M.F.R.; Silva, A.M.T. Occurrence and Removal of Organic Micropollutants: An Overview of the Watch List of EU Decision 2015/495. Water Res. 2016, 94, 257-279. [CrossRef] [PubMed]

17. Huebner, M.; Weber, E.; Niessner, R.; Boujday, S.; Knopp, D. Rapid Analysis of Diclofenac in Freshwater and Wastewater by a Monoclonal Antibody-Based Highly Sensitive ELISA. Anal. Bioanal. Chem. 2015, 407, 8873-8882. [CrossRef] [PubMed]

18. Zhang, Y.; Geißen, S.U.; Gal, C. Carbamazepine and Diclofenac: Removal in Wastewater Treatment Plants and Occurrence in Water Bodies. Chemosphere 2008, 73, 1151-1161. [CrossRef] [PubMed]

19. Schröder, P.; Helmreich, B.; Škrbić, B.; Carballa, M.; Papa, M.; Pastore, C.; Emre, Z.; Oehmen, A.; Langenhoff, A.; Molinos, M.; et al. Status of Hormones and Painkillers in Wastewater Effluents Across Several European States-Considerations for The EU Watch List Concerning Estradiols and Diclofenac. Environ. Sci. Pollut. Res. 2016, 23, 12835-12866. [CrossRef] [PubMed]

20. Petrovic, M.; de Alda, M.J.; Diaz-Cruz, S.; Postigo, C.; Radjenovic, J.; Gros, M.; Barcelo, D. Fate and Removal of Pharmaceuticals and Illicit Drugs in Conventional and Membrane Bioreactor Wastewater Treatment Plants and by Riverbank Filtration. Philos. Trans. A Math. Phys. Eng. Sci. 2009, 367, 3979-4003. [CrossRef] [PubMed]

21. Swan, G.; Naidoo, V.; Cuthbert, R.; Green, R.E.; Pain, D.J.; Swarup, D.; Prakash, V.; Taggart, M.; Bekker, L.; Das, D.; et al. Removing the Threat of Diclofenac to Critically Endangered Asian Vultures. PLoS Biol. 2006, 4, 395-402. [CrossRef] [PubMed]

22. Brodin, T.; Piovano, S.; Fick, J.; Klaminder, J.; Heynen, M.; Jonsson, M. Ecological Effects of Pharmaceuticals in Aquatic Systems-Impacts through Behavioural Alterations. Philos. Trans. R. Soc. B 2014, 369. [CrossRef] [PubMed]

23. Yu, H.; Nie, E.; Xu, J.; Yan, S.; Cooper, W.J.; Song, W. Degradation of Diclofenac by Advanced Oxidation and Reduction Processes: Kinetic Studies, Degradation Pathways and Toxicity Assessments. Water Res. 2013, 47, 1909-1918. [CrossRef] [PubMed]

24. Mehinto, A.C.; Hill, E.M.; Tyler, C.R. Uptake and Biological Effects of Environmentally Relevant Concentrations of the Nonsteroidal Anti-inflammatory Pharmaceutical Diclofenac in Rainbow Trout (Oncorhynchus mykiss). Environ. Sci. Technol. 2010, 44, 2176-2182. [CrossRef] [PubMed]

25. Xekoukoulotakis, N.P.; Xinidis, N.; Chroni, M.; Mantzavinos, D.; Venieri, D.; Hapeshi, E.; Fatta-Kassinos, D. UV-A/TiO2 Photocatalytic Decomposition of Erythromycin in Water: Factors Affecting Mineralization and Antibiotic Activity. Catal. Today 2010, 151, 29-33. [CrossRef]

26. Brayfield, A. Martindale: The Complete Drug Reference, 38th ed.; Pharmaceutical Press: London, UK, 2014.

27. Lange, F.; Cornelissen, S.; Kubac, D.; Sein, M.M.; von Sonntag, J.; Hannich, C.B.; Golloch, A.; Heipieper, H.J.; Möder, M.; von Sonntag, C. Degradation of Macrolide Antibiotics by ozone: A Mechanistic Case Study with Clarithromycin. Chemosphere 2006, 65, 17-23. [CrossRef] [PubMed]

28. Kanoh, S.; Rubin, B.K. Mechanisms of Action and Clinical Application of Macrolides as Immunomodulatory Medications. Clin. Microbiol. Rev. 2010, 23, 590-615. [CrossRef] [PubMed]

29. Joint Formulary Committee. British National Formulary, 71st ed.; British National Formulary: London, UK, 2016. 
30. CAP Guideline Working Group. Annotated BTS Guideline for the Management of CAP in Adults 2015; British Thoracic Society: London, UK, 2015.

31. Rubinstein, E. Comparative Safety of the Different Macrolides. Int. J. Antimicrob. Agents 2001, 18, 71-76. [CrossRef]

32. Abu-Gharbieh, E.; Vasina, V.; Poluzzi, E.; De Ponti, F. Antibacterial Macrolides: A Drug Class with a Complex Pharmacological Profile. Pharmacol. Res. 2004, 50, 211-222. [CrossRef] [PubMed]

33. Albert, R.K.; Schuller, J.L. Macrolide Antibiotics and the Risk of Cardiac Arrhythmias. Am. J. Respir. Crit. Care Med. 2014, 189, 1173-1180. [CrossRef] [PubMed]

34. Le-Minh, N.; Khan, S.J.; Drewes, J.E.; Stuetz, R.M. Fate of Antibiotics during Municipal Water Recycling Treatment Processes. Water Res. 2010, 44, 4295-4323. [CrossRef] [PubMed]

35. Watanabe, H.; Tamura, I.; Abe, R.; Takanobu, H.; Nakamura, A.; Suzuki, T.; Hirose, A.; Nishimura, T.; Tatarazako, N. Chronic Toxicity of an Environmentally Relevant Mixture of Pharmaceuticals to Three Aquatic Organisms (Alga, Daphnid, and Fish). Environ. Toxicol. Chem. 2016, 35, 996-1006. [CrossRef] [PubMed]

36. Baumann, M.; Weiss, K.; Maletzki, D.; Schüssler, W.; Schudoma, D.; Kopf, W.; Kühnen, U. Aquatic Toxicity of the Macrolide Antibiotic Clarithromycin and Its Metabolites. Chemosphere 2015, 120, 192-198. [CrossRef] [PubMed]

37. Liu, J.; Lu, G.; Xie, Z.; Zhang, Z.; Li, S.; Yan, Z. Occurrence, Bioaccumulation and Risk Assessment of Lipophilic Pharmaceutically Active Compounds in the Downstream Rivers of Sewage Treatment Plants. Sci. Total Environ. 2015, 511, 54-62. [CrossRef] [PubMed]

38. American Society of Health-System Pharmacists (ASHP). AHFS Clinical Drug Information; ASHP: Bethesda, MD, USA, 2016.

39. Zhang, C.; Li, Y.; Wang, C.; Niu, L.; Cai, W. Occurrence of Endocrine Disrupting Compounds in Aqueous Environment and their Bacterial Degradation: A Review. Crit. Rev. Environ. Sci. Technol. 2016, 46, 1-59. [CrossRef]

40. Kostich, M.; Flick, R.; Martinson, J. Comparing Predicted Estrogen Concentrations with Measurements in US Waters. Environ. Pollut. 2013, 178, 271-277. [CrossRef] [PubMed]

41. Clouzot, L.; Marrot, B.; Doumenq, P.; Roche, N. 17 $\alpha$-Ethinylestradiol: An Endocrine Distrupter of Great Concern. Analytical Methods and Removal Processes Applied to Water Purification. A Review. Environ. Prog. 2008, 27, 383-396. [CrossRef]

42. Google Trends. Available online: http://www.google.com/trends (accessed on 25 April 2016).

43. Jun, S.P.; Park, D.H. Consumer Information Search Behavior and Purchasing Decisions: Empirical Evidence from Korea. Technol. Forecast. Soc. 2016, in press. [CrossRef]

44. McCallum, M.L.; Bury, G.W. Public Interest in the Environment is Falling: A Response to Ficetola (2013). Biodivers. Conserv. 2014, 23, 1057-1062. [CrossRef]

45. Vosen, S.; Schmidt, T. Forecasting Private Consumption: Survey-Based Indicators vs. Google Trends. J. Forecast. 2011, 30, 565-578. [CrossRef]

46. Scharkow, M.; Vogelgesang, J. Measuring the Public Agenda Using Search Engine Queries. Int. J. Public Opin. Res. 2011, 23, 104-113. [CrossRef]

47. Nuti, S.V.; Wayda, B.; Ranasinghe, I.; Wang, S.; Dreyer, R.P.; Chen, S.I.; Murugiah, K. The Use of Google Trends in Health Care Research: A Systematic Review. PLoS ONE 2014, 9, e109583. [CrossRef] [PubMed]

48. Zhou, X.; Ye, J.; Feng, Y. Tuberculosis Surveillance by Analyzing Google Trends. IEEE Trans. Biomed. Eng. 2011, 58, 2247-2254. [CrossRef] [PubMed]

49. Alicino, C.; Bragazzi, N.L.; Faccio, V.; Amicizia, D.; Panatto, D.; Gasparini, R.; Icardi, G.; Orsi, A. Assessing Ebola-Related Web Search Behaviour: Insights and Implications from an Analytical Study of Google Trends-Based Query Volumes. Infect. Dis. Poverty 2015, 4, 54. [CrossRef] [PubMed]

50. Ingram, D.G.; Matthews, C.K.; Plante, D.T. Seasonal Trends in Sleep-Disordered Breathing: Evidence from Internet Search Engine Query. Sleep Breath. 2015, 19, 79-84. [CrossRef] [PubMed]

51. Brigo, F.; Lochner, P.; Tezzon, F.; Nardone, R. Web Search Behavior for Multiple Sclerosis: An Infodemiological Study. Mult. Scler. Relat. Disord. 2014, 3, 440-443. [CrossRef] [PubMed]

52. Wang, H.W.; Chen, D.R.; Yu, H.W.; Chen, Y.M. Forecasting the Incidence of Dementia and Dementia-Related Outpatient Visits with Google Trends: Evidence from Taiwan. J. Med. Internet Res. 2015, 17, e264. [CrossRef] [PubMed] 
53. Brigo, F.; Igwe, S.C.; Ausserer, H.; Nardone, R.; Tezzon, F.; Bongiovanni, L.G.; Trinka, E. Why Do People Google Epilepsy? An Infodemiological Study of Online Behavior for Epilepsy-Related Search Terms. Epilepsy Behav. 2014, 31, 67-70. [CrossRef] [PubMed]

54. Bragazzi, N.L.; Bacigaluppi, S.; Robba, C.; Nardone, R.; Trinka, E.; Brigo, F. Infodemiology of Status Epilepticus: A Systematic Validation of the Google Trends-Based Search Queries. Epilepsy Behav. 2016, 55, 120-123. [CrossRef] [PubMed]

55. Linkov, F.; Bovbjerg, D.H.; Freese, K.E.; Ramanathan, R.; Eid, G.M.; Gourash, W. Bariatric Surgery Interest Around the World: What Google Trends Can Teach Us. Surg. Obes. Relat. Dis. 2014, 10, 533-538. [CrossRef] [PubMed]

56. Rosenkrantz, A.B.; Prabhu, V. Public Interest in Imaging-Based Cancer Screening Examinations in the United States: Analysis Using a Web-Based Search Tool. AJR Am. J. Roentgenol. 2016, 206, 113-118. [CrossRef] [PubMed]

57. Whitsitt, J.; Karimkhani, C.; Boyers, L.N.; Lott, J.P.; Dellavalle, R.P. Comparing Burden of Dermatologic Disease to Search Interest on Google Trends. Dermatol. Online J. 2015, 21, 25612125.

58. Ingram, D.G.; Plante, D.T. Seasonal Trends in Restless Legs Symptomatology: Evidence from Internet Search Query Data. J. Clin. Sleep Med. 2013, 14, 1364-1368. [CrossRef] [PubMed]

59. Zhang, Z.; Zheng, X.; Zeng, D.D.; Leischow, S.J. Information Seeking Regarding Tobacco and Lung Cancer: Effects of Seasonality. PLoS ONE 2015, 10, e0117938. [CrossRef] [PubMed]

60. Cavazos-Rehg, P.A.; Krauss, M.J.; Spitznagel, E.L.; Lowery, A.; Grucza, R.A.; Chaloupka, F.J.; Bierut, L.J. Monitoring of Non-Cigarette Tobacco Use Using Google Trends. Tob. Control 2015, 24, 249-255. [CrossRef] [PubMed]

61. Davidson, M.W.; Haim, D.A.; Radin, J.M. Using Networks to Combine Big Data and Traditional Surveillance to Improve Influenza Predictions. Sci. Rep. 2015, 5, 8154. [CrossRef] [PubMed]

62. Dukic, V.; Lopes, H.F.; Polson, N.G. Tracking Epidemics with Google Flu Trends Data and a State-Space SEIR Model. J. Am. Stat. Assoc. 2012, 170, 1410-1426. [CrossRef]

63. McCallum, M.L.; Bury, G.W. Google Search Patterns Suggest Declining Interest in the Environment. Biodivers. Conserv. 2013, 22, 1355-1367. [CrossRef]

64. Nijman, V. CITES-listings, EU Eel Trade Bans and the Increase of Export of Tropical Eels out of Indonesia. Mar. Policy 2015, 58, 36-41. [CrossRef]

65. Schuetz, J.; Soykan, C.U.; Distler, T.; Langham, G. Searching for Backyard Birds in Virtual Words: Internet Queries Mirror Real Species Distributions. Biodivers. Conserv. 2014, 24, 1147-1154. [CrossRef]

66. Ficetola, G.F. Is Interest Toward the Environment Really Declining? The Complexity of Analyzing Trends Using Internet Search Data. Biodivers. Conserv. 2013, 22, 2983-2988. [CrossRef]

67. Google Trends. Data Normalization. 2016. Available online: https://support.google.com/trends/answer/ 4365533 (accessed on 8 February 2016).

68. NHS Digital. Available online: http://digital.nhs.uk/ (accessed on 20 July 2016).

69. Prescriptions Dispensed in the Community. Available online: http://gov.wales/statistics-and-research/ prescriptions-dispensed-community/?lang=en/ (assessed on 24 July 2016).

70. Information Services Division. Available online: http://www.isdscotland.org/Health-Topics/Prescribingand-Medicines/Community-Dispensing/Prescription-Cost-Analysis/ (assessed on 22 July 2016).

71. Business Services Organisation. Available online: http://www.hscbusiness.hscni.net/services/1806.htm (assessed on 26 July 2016).

72. Diclofenac Tablets Now Only Available as a Prescription Medicine. Available online: https://www.gov. $\mathrm{uk}$ /government/news/diclofenac-tablets-now-only-available-as-a-prescription-medicine (accessed on 8 August 2005).

73. Scopus. Available online: http:/ /www.scopus.com (accessed on 12 August 2016).

74. Medicines and Healthcare products Regulatory Agency (MHRA). New Recommendations after a Europe-Wide Review of Cardiovascular Safety; MHRA: London, UK, 2013.

75. Brozinski, J.M.; Lahti, M.; Meierjohann, A.; Oikari, A.; Kronberg, L. The Anti-Inflammatory Drugs Diclofenac, Naproxen and Ibuprofen are found in the Bile of Wild Fish Caught Downstream of a Wastewater Treatment Plant. Environ. Sci. Technol. 2013, 47, 342-348. [CrossRef] [PubMed]

76. Public Health England. Management of Infection Guidance for Primary Care for Consultation and Local Adaptation; Public Health England: London, UK, 2016. 
77. Public Health England. Sexually Transmitted Infections and Chlamydia Screening in England, 2015; Public Health England: London, UK, 2016.

78. Southern, K.W.; Barker, P.M.; Solis-Moya, A.; Patel, L. Macrolide Antibiotics for Cystic Fibrosis. Cochrane Database Syst. Rev. 2012, 11, CD002203. [PubMed]

79. National Institute for Health and Care Excellence. Antimicrobial Stewardship: Systems and Processes for Effective Antimicrobial Medicine Use; National Institute for Health and Care Excellence: London, UK, 2015.

80. British Poultry Council, 2004. Available online: http://www.britishpoultry.org.uk/areas-of-work/animalhealth-and-welfare/antibiotic-use-in-poultry/ (accessed on 4 September 2016).

81. NHS-Contraception Guide. Available online: http://www.nhs.uk/conditions/contraception-guide/pages/ where-can-i-get-contraception.aspx/ (accessed on 22 September 2016).

(C) 2016 by the authors; licensee MDPI, Basel, Switzerland. This article is an open access article distributed under the terms and conditions of the Creative Commons Attribution (CC-BY) license (http://creativecommons.org/licenses/by/4.0/). 